\title{
New Solvency Regulation: What CEOs of Insurance Companies Think
}

\author{
Markus Kreutzer ${ }^{\mathrm{a}}$ and Joël Wagner ${ }^{\mathrm{b}}$ \\ ${ }^{a}$ Institute of Management, University of St. Gallen, Dufourstrasse 40a, 9000 St. Gallen, Switzerland. \\ E-mail: markus.kreutzer@unisg.ch \\ b Institute of Insurance Economics, University of St. Gallen, Tannenstrasse 19, Kirchlistrasse 2, \\ 9000 St. Gallen, Switzerland. \\ E-mail: joel.wagner@unisg.ch
}

Current reforms of solvency regulation in Europe include the Swiss Solvency Test, already in force in Switzerland since 2011, and the planned move by the European Union from the Solvency I to the Solvency II framework over the coming years. These changes bring with them more stringent requirements in many areas and thus have a broad impact on the European insurance industry. The scope of this paper is to analyse, on the basis of an industry survey, the perceived magnitude of the impact, the effects and the uncertainty accompanying these reforms. The study highlights significant differences in perception by country, size of business and dominant business line. Furthermore, selected perceived effects of new solvency regulation are shown to have a significant impact on the (planned) sites and scope of business model adaptation.

The Geneva Papers (2013) 38, 213-249. doi:10.1057/gpp.2013.5

Keywords: solvency regulation; strategic adaptation; industry survey

Submitted 18 June 2012; accepted 8 January 2013; published online April 2013

\section{Introduction}

Regulatory frameworks governing solvency requirements are undergoing far-reaching reforms in Europe. The European Union (EU) is planning to replace the current Solvency I regulations with the Solvency II framework. Meanwhile, the Swiss Solvency Test (SST), a very similar framework to Solvency II, has been in force in Switzerland since 2011. The changes to insurance supervision aim to further improve customer protection from company default. ${ }^{1}$ Although European regulators recognised the need for reform prior to the recent financial crisis (work on both Solvency II and the SST was initiated before), the recent turmoil and the lessons learned from it have provided further impetus for these reform programmes. ${ }^{2}$ The aforementioned new frameworks both replace a volume-based balance-sheet approach by considering the entire risk

\footnotetext{
${ }^{1}$ An examination of the regulation of insurance markets and the arguments for solvency regulation when consumers are informed of the insurer's insolvency risk can be found, for example, in Rees et al. (1999). Empirical evidence concerning the effects of solvency regulation on the number of companies and frequency of insolvencies is reported, for example, by Munch and Smallwood (1980).

${ }^{2}$ See Committee of European Insurance and Occupational Pensions Supervisors (CEIOPS) (2009).
} 
profile of insurance firms. The reforms affect the calculation of capital requirements, have a strong impact on the valuation of assets and liabilities, and set new rules for supervision, transparency and governance. It requires a great effort in terms of strategic adaptation and internal implementation from all industry players. Despite the fact that the phasing-in period for Solvency II is approaching (2013), some details remain uncertain. The SST and Solvency II are widely discussed topics, with a strong annual increase in the number of references to them in newspaper articles. According to Dow Jones Factiva, 2008 saw just 1,200 Solvency II-related articles, while 5,000 were recorded in 2011 and an estimated 10,000 are expected for 2012 (estimate based on records from January to April 2012). A similar increase can be seen in the number of references to the SST.

On the basis of an insurance industry survey conducted with CEOs of insurance firms in Switzerland, Germany and Austria in summer 2011, we study the perceived impact, effects and uncertainty accompanying the regulatory reforms and link these perceptions to the resulting (intended) management actions. With an overall response rate of 48.4 per cent, we base our analyses on 70 primary insurers (excluding the eight pure reinsurers in our sample). Our key analyses reflect (1) significant differences in the considered countries representative of two different regulatory environments (Switzerland vs EU), (2) differences due to business mix (life vs non-life) and (3) differences based on firm size (total premium volume). After analysing the relative importance of these three factors, we (4) examine the additional role of the perceived effects of solvency regulation on adaptation.

This analysis contributes to two separate academic literature streams. First, and most generally, there is a strand of (strategic) management literature that looks at the impact of institutional change such as government regulation and deregulation on firms' behaviour, strategic choice and performance - see, for example, Delmas et $a .^{3}$ Regulatory events have been commonly conceptualised in terms of the punctuated equilibrium paradigm, where the shift in regulatory regimes triggers industry upheavals that are similar to discontinuous change after a period of relative stability. ${ }^{4}$ Empirical studies interested in company-specific change in the face of different regulatory events have been conducted in industries, where regulatory interventions have been especially pervasive, including banking, ${ }^{5}$ airlines, ${ }^{6}$ electric utilities ${ }^{7}$ and health care. ${ }^{8}$ Almost no studies have focused on the insurance industry and on recent solvency regulation in particular. The few that exist include Pottier, ${ }^{9}$ where insurers' optimal behaviour is assessed with regard to cost efficiency and state regulation. Management studies' empirical findings on the responses of firms in other industries identify reactions such as modifying resource allocation, increasing capital

\footnotetext{
${ }^{3}$ Delmas et al. (2007).

${ }^{4}$ Haveman et al. (2001).

${ }^{5}$ Flier et al. (2001).

${ }^{6}$ Engau and Hoffmann (2011a).

${ }^{7}$ Russo (1992).

${ }^{8}$ Cook et al. (1983).

${ }^{9}$ Pottier (2010).
} 
expenditures, postponing investment decisions, ${ }^{10}$ abandoning major products, ${ }^{11}$ diversifying, ${ }^{7}$ backward integration, ${ }^{7}$ searching for higher margins in more defensible, unregulated niches by pursuing domain expansion, ${ }^{4}$ and selecting less risky strategies. ${ }^{12}$

Second, there is a strand of literature that focuses on the effects of solvency requirements on insurance companies. Ashby, ${ }^{13}$ for example, investigates the causes of the last banking crisis and the lessons to be learned for the regulation of insurance firms. In a paper by Eling et al., ${ }^{14}$ the characteristics and major benefits of the SST, and the economic effects and market implications of changes in asset and liability management are discussed. Solvency II regulation and financial market interaction is also the subject of the analysis by Butt. ${ }^{15}$ The implications of market-consistent asset and liability management at life insurance companies in the light of Solvency II are investigated by Van Bragt et al. ${ }^{16}$

Our work is novel in several ways. While most of existing industry surveys (see section "Review of current reforms and new challenges for the industry" for a review) typically cover only one regulatory framework and one specific aspect affected (e.g. focus on capital requirements, implementation challenges or strategic issues), we take a broader, integrative approach. We use a questionnaire including 60 dimensions and an identical survey setup over three countries. This allows us to conduct crosscountry comparisons and to assess the relative importance of several aspects and their interactions which have to date only been analysed separately. In our statistical analysis, we control for alternative explanations and use a step-wise regression analysis to gain an understanding of the additional explanatory power of certain variables.

The remainder of this paper is organised as follows: The next section summarises current developments in solvency regulation in Europe ("Review of current reforms and new challenges for the industry") and provides an explanation of our research hypotheses ("Hypotheses for research"). In the subsequent section we outline the pursued methodology: the first subsection describes the data collection and the sample of respondents; in the second subsection the different topics of the survey instrument are detailed; in the third sub-section we outline the results of our factor analysis and give the relevant construct definition for the further analyses. The survey results are presented and discussed in the section "Survey results": the first subsection deals with relevant differences by country, business type and company size; in the second subsection the relative predictive role of the latter grouping variables is studied through regression analyses; in the third subsection we evaluate the additional role of the perceived effects driving strategic adaptation; we discuss the most important results in the fourth subsection. The conclusion in the final section reviews our key findings. In the first part of the appendix the survey questions are given in detail; in the second part we present further details of the survey results.

\footnotetext{
${ }^{10}$ Hoffmann et al. (2009).

${ }^{11}$ Ungson et al. (1985).

12 Birnbaum (1984).

13 Ashby (2011).

${ }^{14}$ Eling et al. (2008).

15 Butt (2007).

${ }^{16}$ Van Bragt et al. (2010).
} 


\section{Current developments in solvency regulation}

\section{Review of current reforms and new challenges for the industry}

New solvency regulation frameworks in the EU and Switzerland enforce the supervision of insurance and reinsurance undertakings while further improving customer protection. The aim is to ensure insurance companies' risk-bearing ability, to promote the improvement of quantitative and qualitative internal risk management functions, and to enhance disclosure to supervisory authorities and partially investors.

The new EU solvency regulation system is being adopted in a two-stage process. In 2004, Solvency I was introduced, modifying the local (harmonised) capital standards introduced in the 1970s. ${ }^{17}$ While the EU Solvency I directive has revised and updated European solvency regimes by imposing minimum capital requirements based on liability-related, volume-based ratios, new solvency reforms have a much wider scope. In Switzerland, the SST white paper ${ }^{18}$ sets out a new concept for solvency regulation, comprising the introduction of "market-consistent" valuation, a standard model and requirements for internal modelling, scenario computation and reporting. Solvency II aims to take primarily an enterprise risk management approach that looks at the entire risk profile of an insurance company. This makes it similar in many aspects to the SST, introduced in 2006 and in force in Switzerland since 2011. ${ }^{19}$ Standards and guidelines are expected to cover internal models, capital requirements and the valuation of assets and liabilities, as well as rules for supervision, transparency and governance. An initial discussion of the motivation behind Solvency II can be found in European Commission. ${ }^{20}$ The standards are defined in a European Union directive, ${ }^{21}$ expected to be amended by the "Omnibus II" proposal. ${ }^{22}$ The latest reforms have been initiated by the EU and local financial market authorities; today, Solvency II is one of the core activities of the European Insurance and Occupationals Pensions Authority (EIOPA). For testing purposes, several quantitative impact studies have been carried out. In March 2011, EIOPA published the fifth quantitative impact study (QIS5) report. QIS5 is the final fully comprehensive assessment of future pillar 1 quantitative requirements and is considered a major step towards the implementation of Solvency II. The publication of the QIS5 report represents a key milestone in the finalisation of the Solvency II project. ${ }^{23}$ The participation rate has doubled from the fourth to the fifth QIS, which following EIOPA shows that Solvency II is a key priority to insurers. A majority of the participants think they should be well prepared or even ahead in their preparations. ${ }^{24}$ Furthermore, according to the report, challenges to implementation are the complexity, data quality, data management and IT. Current areas that need improvement include quality and quantity of resources, understanding of the

\footnotetext{
${ }^{17}$ European Union (2002a, b).

${ }^{18}$ Swiss Federal Office of Private Insurance (FOPI) (2004).

${ }^{19}$ Holzmüller (2009).

${ }^{20}$ European Commission (1999).

${ }^{21}$ European Union (2009).

${ }^{22}$ European Commission (2011).

${ }^{23}$ The technical specifications of the fifth study can be found in European Commission (2010).

${ }^{24}$ EIOPA (2011).
} 
requirements and operational implementation, and the application of the requirements from pillars 2 and 3 (corporate governance, disclosure and transparency, see below). The current EU Solvency I rules will remain in force until (at least) 1 January 2014 (see also www.ec.europa.eu/internal_market/insurance/index_en.htm). The new Solvency II framework is expected to be implemented in 2013 via a phasing-in period, and enter into force from 2014 (see www.eiopa.europa.eu).

The planned EU Solvency II and the Swiss SST frameworks both focus on quantitative and qualitative risk management. Both systems require a comprehensive "risk-based approach", considering insurance companies as a whole and thus breaking with the earlier approach that involved mainly isolated consideration of risks. Similarly to the Basel II regulation in the banking industry, new solvency frameworks follow a three-pillar approach, that is, besides the quantitative aspects, qualitative issues and reporting requirements are also addressed. ${ }^{25}$ The first pillar describes standard quantitative requirements with regard to the overall solvency of the insurance company. Minimum capital requirements (MCR) and solvency capital requirements (SCR) are defined ${ }^{26}$ and solvency frameworks require that the available (solvency) capital is higher than the SCR and the MCR ${ }^{27}$ The second pillar focuses on qualitative requirements. The main components are principles of internal risk management, transparent risk control, accurate data management, tight matching of solvency and decision-making, and the corresponding supervisory interventions. ${ }^{28}$ The third pillar addresses supervisory reporting and public disclosure. Market transparency and disclosure requirements thus directly link Solvency II to international reporting standards. ${ }^{21}$

Several industry studies conclude that the implementation of SST and Solvency II have required and continue to require great efforts from insurance companies: IfB-HSG/KPMG ${ }^{29}$ analyses opportunities and risks arising from the new regulatory frameworks. The Boston Consulting Group $(\mathrm{BCG})^{30}$ studies the impact of current reforms on business strategies concluding that new rules will introduce more variability into the risk-adjusted profitability of businesses and products. Furthermore, the report reasons that, for example, the new rules will reshape the industry landscape in some countries, creating a new balance of power or intensifying consolidation. I.VW-HSG/Accenture ${ }^{31}$ reports that the perceived dynamics of change in the German-speaking insurance sector are determined primarily by the external factor of regulation: "tougher regulations on the ability to assume risk and on transparency

${ }^{25}$ An overview, critical analysis and comparative assessment of the principles of insurance regulation with a focus on Solvency II, the SST and the United States' risk-based capital standards can be found, for example, in Eling et al. (2007); Eling and Holzmüller (2008); Doff (2008); Holzmüller (2009) and Klein (2012).

${ }^{26}$ European Commission (2010); Wagner and Zemp (2012).

${ }^{27}$ An insurer's failure to meet its MCR will be subject to immediate regulatory intervention. A failure to meet the SCR but meeting or exceeding the MCR may be subject to regulatory action based on whether regulators believe corrective action is warranted.

${ }^{28}$ Eling et al. (2007).

${ }^{29}$ IfB-HSG/KPMG (2011).

${ }^{30}$ Boston Consulting Group (BCG) (2010).

${ }^{31}$ I.VW-HSG/Accenture (2010, p. 12). 
are putting a lasting mark on the business models of insurance companies". Similarly Morgan Stanley and Oliver Wyman ${ }^{32}$ describe Solvency II as a "catalyst for a fundamental reappraisal of traditional insurance business models". A report by PricewaterhouseCoopers $(\mathrm{PwC})^{33}$ deals with the results of a survey on EU insurers' readiness for Solvency II implementation ("most respondents are confident that they'll meet the deadlines", see p. 4), and $\mathrm{PwC}^{34}$ compares, in a Swiss industry survey, the perceived efforts of SST, Solvency II and the changes brought about by the IFRS 4 Phase II reporting reforms.

The $\mathrm{PwC}^{33}$ study reveals, for example, that a significant proportion of firms have ambitious plans for Solvency II, but only 25 per cent see the directive as an opportunity to sharpen competitive differentiation. Finally, we should mention the work by Wagner and Zemp ${ }^{35}$ discussing the views of and challenges faced by the various stakeholders including the insurers' management teams, investors and the regulator. The impact in terms of costs and benefits for the industry and the customers is analysed in a work by Lorson et al. ${ }^{36}$ which develops a conceptual integrative model for Solvency II. ${ }^{37}$

In conclusion, new solvency requirements are expected to transform the European insurance industry landscape, with capabilities, preparation and anticipation being key to determining a company's place in new hierarchies. The impact on business attractiveness, profitability and product design is expected to vary across countries, lines of business and products. Furthermore, capital requirements and the need for additional funding will be strongly linked to the quality of risk management. The implementation of effective risk management strategies incorporating the relevant fields of financial, insurance and operational risks represents an ongoing challenge. In addition to quantitative modelling, the continuous development of transparent processes, their permanent monitoring, and reporting processes and systems must be traceable and documented. The implementation of the new framework is accompanied by changes in the roles and responsibilities within companies, with implications for corporate governance. For example, risk management functions are to be detached from operations. However, the focus should not be solely on technical and operational issues but must rather include strategic adaptation to the effects of the new solvency environment. The comprehensive requirements of the new solvency frameworks imply substantial changes to the risk awareness and culture of insurance companies.

\footnotetext{
${ }^{32}$ Morgan Stanley and Oliver Wyman (2010).

${ }^{33}$ PricewaterhouseCoopers (PwC) (2010).

${ }^{34}$ PwC (2011).

${ }^{35}$ Wagner and Zemp (2012).

${ }^{36}$ Lorson et al. (2013).

${ }^{37}$ The European insurance and reinsurance federation discusses, in Comité Européen des Assurances (CEA) (2010), why excessive capital requirements may harm consumers, insurers and the economy. CEA (2007) estimates the impact of Solvency II on the insurers' administrative costs and argues that if the reforms lead to an inappropriate framework, that is, not a risk-based economic framework in line with industry best practice, managing costs will be challenging.
} 


\section{Hypotheses for research}

The companies' perceptions and assessment of the regulatory impact and the management actions required are at the centre of our present analysis. In this paper, our aim is to assess differences in perception and in the (planned) actions within the industry based on data collected in an international survey (see Appendix) conducted in summer 2011. The results we present in the following include the responses obtained in two EU countries (Germany and Austria) and Switzerland. As discussed above in the introduction, to our knowledge, no representative study has yet examined the perceived effects and strategic adaptation, including its scope and sites, in such detail (60 question items) in a survey covering three countries, taking into account the different elements of response while also aggregating them and analysing their relationship. On this basis, we intend to go further than a mere presentation of the survey results; our research will focus on the following questions:

1. Are there significant differences in insurance companies' perceptions and adaptation behaviour (or plans) in the face of solvency regulation reforms between SST and Solvency II countries?

2. What is the influence of a company's type of business or dominant business line on the perception and adaptation plans for the new solvency frameworks?

3. Is firm size an influencing variable and how relevant is it compared with the territory or the business type?

4. What is the influence of the perception of the effects of solvency regulation on companies' strategic adaptation?

Research question 1 looks at potential differences between countries. It is reasonable to expect that the impact of reforms on insurers will vary depending on a number of factors, including the extent to which they have already implemented risk management principles and processes that will be required by these reforms. Our survey was conducted in summer 2011 - a time when the two groups of countries were at different stages in the development of the new regulatory frameworks. As the SST is already in force and Solvency II is still a work in progress, we expect differences in the perceived impact (e.g. certainty about the framework, pace of change) between the two groups of countries, with Swiss insurance firms being on average more certain and perceiving less time pressure to comply with new regulations, as they have been familiar with SST for some time and are thus well-prepared to deal with the new solvency regulation. With respect to differences in strategic adaptation, two opposing arguments exist. On the one hand, one might expect the strategic adaptation to be aligned across all surveyed countries, as both regulatory frameworks build on similar ideas (e.g. quantitative and qualitative requirements). On the other hand, however, one could argue that Swiss firms needing to adapt are likely to have already adapted their internal and external strategies and will therefore report lower levels of strategic activity.

Question 2 relates to the different impact of new requirements on the various business lines and products. With the new solvency regulation, the insurer's exposure to different types of risks and the uncertainty about the future, in particular the time aspect of long-term liabilities, are integrated for the first time into the solvency 
assessment (in contrast to the previous Solvency I regulation). In our analysis we will focus on the differences between life and non-life business. Capital requirements may increase for several life insurance products that have unpredictable cash flows or longterm guarantees (e.g. classical life insurance contracts) or non-life products that may involve long-tail liabilities (e.g. third-party liability) or cover catastrophic outcomes (exposure to catastrophe risk). As a rule of thumb, the more long-tail liabilities and the more risky assets, the greater the negative impact. ${ }^{38}$ Following this reasoning, differences between life and non-life business strongly depend on the specific underwriting portfolio of individual insurers. Since life insurance business is characterised by long-term guarantees on the liability side and a long-term investment strategy (e.g. high share of real estate) on the asset side, we expect insurers with a higher share of life business to be more affected by the new solvency regulations and to respond more radically.

Question 3 relates to the size of the firms. In terms of the models used today, for example in companies' asset and liability management departments, we assume that large insurers largely rely on their own models and economic analysis, while small and medium-sized firms instead tend to use standard tools together with qualitative estimates. We believe that firm size is an important additional differentiator: in general, smaller companies will be at a relative disadvantage due to the cost and complexity of optimising capital models. Furthermore, smaller firms may also incur unnecessarily high capital requirements if they rely solely on the regulator's standard model. Large companies can typically build and use their own internal models (which have to be approved by the regulator). This allows them, by deviating from standard formulations, to differentiate their capital requirements, which may provide a competitive advantage. In addition, larger firms will typically have access to more resources, larger networks and more political relationships, and can make use of broader diversification in many areas.

Research question 4, which has a more exploratory focus, is intended to provide a better understanding of the precise links between the perceived effects (and their perceived magnitude) and (planned) strategic adaptation, that is, what the companies plan to do in terms of adaptation, and what its scope and sites will be. Our aim is to analyse strategic adaptation along the most important points on an insurer's value chain.

In the following section, we will describe the survey in detail and provide summary statistics on the respondents in our sample. In the section, "Survey results" we report and discuss the results of our study.

\section{Methodology and data basis}

In this chapter, we describe our study design and data collection effort ("Data collection"), our survey questionnaire ("Survey instrument"), and the results of the factor analysis we conducted to determine the validity of our measurement instruments ("Results of factor analysis").

\footnotetext{
${ }^{38}$ See also, e.g. BCG (2010).
} 


\section{Data collection}

The survey is designed to collect data on the two main topics - the perceived impact of the new solvency regulations, Solvency II or SST, and the (intended) strategic adaptation to the regulatory framework. The study was conducted in summer 2011, a time when the SST was already in force in Switzerland, and the EU Solvency II framework had reached the stage of the fifth Quantitative Impact Study (see also the section "Current developments in solvency regulation"). To compare the regional impact of Solvency II to that of the SST, we have chosen Germany and Austria to represent the former and Switzerland to represent the latter. As we are also interested in differences arising from the size and the business focus of different firms, we included all insurance companies in these three markets independently of their size or their core business line (life vs non-life).

In total, 161 insurance firms were identified for participation (Switzerland: 50 firms; Germany: 77 firms; Austria: 34 firms). A questionnaire (accompanied by a cover letter, response instructions and a link to the online web-based survey as well as a prepaid return envelope) was sent in summer 2011 via email to the senior executive of each company (typically the Chief Executive Officer), who is considered the primary respondent. Preliminary contact was either established via a preceding phone call announcing the survey or an extended interview of $1-2 \mathrm{~h}$ in 29 organisations. $^{39}$

Representatives from 78 different insurance firms returned usable questionnaires, giving an overall response rate of 48.4 per cent. ${ }^{40}$ This final sample consists of 25 responses from Switzerland (response rate of 50.0 per cent), 31 responses from Germany (response rate of 40.3 per cent) and 22 responses from Austria (response rate of 64.7 per cent). Seventy answers ( 90 per cent of all responses) represent the views of primary life and/or non-life insurers, while eight answers (from Switzerland) are from pure reinsurers. In the following, we will focus solely on the primary insurers. The majority of these 70 respondents is the CEO (41.4 per cent) or holds an executive position at the first hierarchical level (45.7 per cent), such as the CFO or CRO. The remaining nine respondents (12.9 per cent) hold positions such as "head of group regulatory affairs" or "head of enterprise risk management", or are internally responsible for change management and the implementation of the solvency framework.

Table 1 illustrates the sample composition in terms of primary life, primary non-life and mixed primary insurers. In our categorisation we consider insurers with over 50 per cent life premiums (as a proportion of their total premium volume) as (primary) life insurers. Furthermore, we split our overall sample evenly into "large" and "small" companies considered by taking the median total premium volume in our sample as a

39 To further increase their willingness to respond, we guaranteed our respondents to treat their responses anonymously and only report results in an aggregated way.

${ }^{40}$ To avoid a single-respondent bias, we asked the first participants to provide a second top management respondent in their firm. In the firms in which we got a second respondent, we compared their assessment with one of the first respondent without detecting any significant deviations. We took the average of their answers to reflect a more balanced firm perspective. 
Table 1 Number of responding insurance companies and represented premium shares

\begin{tabular}{lcccc}
\hline Insurers & Switzerland & Germany & Austria & Total \\
\hline Total number & 25 & 31 & 22 & 78 \\
Primary & $17(100.0)$ & $31(100.0)$ & $22(100.0)$ & $70(100.0)$ \\
Pure reinsurers & 8 & - & - & 8 \\
& & & & $10(7.5)$ \\
Primary life & $3(24.8)$ & $5(2.7)$ & $2(5.5)$ & $25(2.0)$ \\
Primary non-life & $7(0.7)$ & $7(1.4)$ & $11(11.1)$ & $35(90.5)$ \\
Mixed primary & $7(74.6)$ & $19(95.9)$ & $9(83.4)$ & $27(63.9)$ \\
& $7(82.4)$ & $15(62.6)$ & $5(17.6)$ & $43(36.9)$ \\
Considered as life & $10(17.6)$ & $16(37.4)$ & $17(82.4)$ & $35(96.8)$ \\
Considered as non-life & $9(99.2)$ & $22(98.6)$ & $4(74.9)$ & $35(3.2)$ \\
Large companies & $8(0.8)$ & $9(1.4)$ & $18(25.1)$ & \\
Small companies & & & & \\
\hline
\end{tabular}

The structure of the sample in each country (in terms of premium volume) is given by the numbers in parentheses that reflect for each category the in-sample premium share in per cent with respect to the total primary insurers' premium volume. The total primary insurer premium volume in the sample ( 100.0 per cent) is $€ 32.8$ billion in Switzerland, $€ 110.8$ billion in Germany and $€ 12.5$ billion in Austria, that is, overall $€ 156.1$ billion in the three countries considered. The reinsurance companies in Switzerland account for an additional $€ 13.2$ billion. Premium volumes reported refer to the values for 2010 as reported in the local authorities' statistics; Swiss francs are converted into $€$ using the rate of $1 \mathrm{CHF}=€ 0.8022$.

threshold (overall median: €499.8 million). For each category, the number of responses and the corresponding premium shares are given.

The total premium volume represented by the sample totals $€ 156.1$ billion (Switzerland: $€ 32.8$ billion, Germany: $€ 110.8$ billion, Austria: $€ 12.5$ billion). The premium shares of the different firm categories are specified in detail in Table 1. While large and small companies are evenly represented in the sample from Switzerland, the sample of German firms mainly consists of companies categorised as large, while in Austria most companies are smaller entities. In total, the large companies represent over 96.8 per cent of the total premium volume in the sample. In the life and non-life category, a majority of firms is classified as non-life (43 vs 27). However, the life insurance companies represent about two-thirds (63.9 per cent) of the sample premium volume (non-life: 36.9 per cent). ${ }^{41}$

We analysed the market coverage of our final sample in terms of market shares. The details on the coverage in all three countries, differentiating between life and non-life business lines, can be found in Table 2. As we cover around two thirds of the market,

${ }^{41}$ To test for potential selection bias, we compared respondent firms with nonrespondent firms in terms of size and business line. Performed $t$-tests reveal statistically significant differences in the premium volume when comparing respondent firms with nonrespondents ( $p$-value $<0.01$ ) in Switzerland and Germany, confirming that nonresponding companies seem to be smaller than responding companies. The nonresponding companies were significantly smaller than the respondents in both countries. In Austria no statistically significant differences are found between the two groups. 
Table 2 Market coverage (in per cent) of the sample

\begin{tabular}{lcccr}
\hline Business line & Switzerland & Germany & Austria & Total \\
\hline Life & 92.6 & 60.5 & 76.9 & 68.2 \\
Non-life & 68.9 & 62.6 & 59.9 & 63.1 \\
Overall & 84.1 & 61.6 & 66.6 & 67.7 \\
\hline
\end{tabular}

Market coverage of the survey answers in the life and non-life business lines in the three countries considered (Switzerland, Germany and Austria). Shares are based on premium figures for 2010 as reported in the local authorities' statistics.

Table 3 Topic categories and number of questions in the survey

\begin{tabular}{clc}
\hline Survey & Topics & Number of questions \\
\hline Part A: & Perceived impact of Solvency II/SST \\
A1 & Magnitude of Solvency II/SST & 4 \\
A2 & Effect of Solvency II/SST & 6 \\
A3 & Pace of Solvency II/SST & 3 \\
A4 & Uncertainty of Solvency II/SST & 7 \\
A5 & Solvency II/SST as threat or opportunity & 7 \\
& & 6 \\
Part B: Strategic adaptation to Solvency II/SST & 6 \\
B1 & Decision-making comprehensiveness and Solvency II/SST \\
B2 & Lobbying and political activity (Solvency II/SST) \\
B3 & Managing uncertainty concerning Solvency II/SST & 10 \\
B4 & Scope of adaptation to Solvency II/SST & 5 \\
B5 & Sites of business model adaptation to Solvency II/SST & 6 \\
\hline
\end{tabular}

we consider our study to be highly representative of the current situation in the insurance industry.

\section{Survey instrument}

The survey comprises 60 question items (see Appendix for the detailed questions), grouped into 10 topics that are summarised in Table 3. In each item, the degree of agreement with the given statement is assessed on a 5-point Likert-type scale ranging from 1 (strongly disagree) to 5 (strongly agree), with the value 3 corresponding to the neutral position for each question (see Appendix A for the scales used).

In the various topic categories, several dimensions are surveyed through multiple questions. We rely on established measures whenever possible. Further details are given below. However, where necessary due to the specific context of insurance regulation, we have also developed new items. Based on an intensive literature review and the 29 qualitative interviews with insurance executives, we developed definitions of the constructs of interest. Then, in order to ensure content validity, we deductively and inductively generated items that represent the content of these constructs in 
a comprehensive way. As mentioned above, we use multi-item scales for all questions. As the survey has been designed specifically for insurance executives, we adapted the wording of the original sources to improve accessibility and provide a close fit with industry practice. In addition, preliminary versions of the questionnaire were reviewed by business academics (with a management and insurance focus) to ensure face validity, and then pretested with managers.

The objective of Part A of the survey is to measure the perceived impact of Solvency II and SST in five different dimensions. In line with existing research, perceptual measures were used "since it is managers' perception of their environment that is expected to affect [subsequent firm behaviour]" (p. 983). ${ }^{42}$

A1 The first topic in Part A measures the perceived magnitude of the new solvency frameworks by using four questions that build on the measures of environmental complexity and turbulence developed by Meznar and $\mathrm{Nigh}^{42}$ (in their study, used as indicators of uncertainty) that fitted our context. Of the original five complexity items (pp. 995-996), ${ }^{42}$ we retained the first three items (representing our items A1.1-3) and of the four turbulence items (p. 995), ${ }^{42}$ we retained the first item (representing our item A1.4).

A2 Topic A2 concerns the perceived effect of Solvency II or the SST on a firm's activities. The scope of regulation is measured in a similar way in Hauptman and Roberts, ${ }^{43}$ a study that analysed the impact of the U.S. Food and Drug Administration's approval process on firms' resources and time. For the present study, we have redeveloped these items in an attempt to reflect the decisive dimensions of an insurer's business model. Thus, we asked for the expected effects of new solvency regulation on the firm's products and services, capital structure, internal processes and structure, risk management, profitability and overall business model.

A3 In addition, we are interested in differences in the perception of the pace of solvency regulation. Our first two items ("preparation time" and "quickness of effects") were developed on the basis of the theoretical work by Kim and Prescott. ${ }^{44}$ Our item three ("pace of change" in the regulatory environment) is based on the turbulence measure's third item from Meznar and Nigh (p. 995). ${ }^{42}$

A4 Topic A4 measures the perceived uncertainty a company has with respect to several features of the solvency frameworks under consideration. The first six of the seven items used were developed on the basis of a conceptual taxonomy by Hoffmann et al., ${ }^{45}$ which distinguishes between five categories of regulatory uncertainty: (1) the basic direction or target - represented by our first two items, (2) the measures and rules - our item A4.3, (3) the implementation process - item A4.4, (4) the interdependence-item A4.5 and (5) regulation-induced uncertainty-item A4.6. The behavioural consequences in item A4.6 are in line with work by Cook et al. ${ }^{8}$ Finally, we have added a final element (A4.7) that represents

\footnotetext{
42 Meznar and Nigh (1995).

${ }^{43}$ Hauptman and Roberts (1987, p. 142).

${ }^{44} \mathrm{Kim}$ and Prescott (2005).

${ }^{45}$ Hoffmann et al. (2008).
} 
the idea that uncertainty can also include uncertainty about the major competitors' strategic responses.

A5 The fifth topic category measures the perception of solvency regulation as an opportunity and/or as a threat. The considered items go back to the work of Thomas and McDaniel, ${ }^{46}$ building on the conceptual paper by Dutton and Jackson $^{47}$ and the authors' questionnaire used in Jackson and Dutton, ${ }^{48}$ which distinguish three strategic issue labels - namely the paired dimensions positivenegative, gain-loss and controllable-uncontrollable. As the controllability aspect is not relevant in our context (as insurance firms do not have choice about whether or not to address changes in regulation), we focus on the positivenegative and gain-loss interpretation. The original scale included six items for positive and four items for negative connotations. Reducing the complexity and the perceived overlap between questions, we decided to keep only three items for each direction (see questions A5.1-A5.6, presented in the Appendix). In addition, statement A.5.7 complements the list by considering existing within-firm capabilities to address new solvency regulation.

The aim of the topics in Part B is to provide an assessment of the (intended) strategic adaptation to Solvency II or SST:

B1 Topic category B1 measures the comprehensiveness with which Solvency II/SST regulation is addressed in firms' decision procedures. It uses an existing five-item measure from Heavey et al., ${ }^{49}$ which builds on prior work by several others. ${ }^{50} \mathrm{We}$ added item B1.2 ("preparing detailed, technical reports on impact of Solvency II/ SST"), based on the work of Birnbaum (p. 149). ${ }^{51}$

B2 Next, corporate response strategies to regulatory uncertainty in terms of lobbying and political activity are measured using existing questions. The first item is derived from work by Engau and Hoffmann, ${ }^{52}$ items B2.2-B2.5 from Hillman et $a l .{ }^{53}$ and Meznar and Nigh, ${ }^{42}$ and the last item (B2.6) from Birnbaum. ${ }^{51}$

B3 The third topic measures the way uncertainty about Solvency II/SST is managed. We adapted an established measure from Engau and Hoffmann ${ }^{52}$ to the context of solvency regulation. They differentiated between "avoidance strategy", measured by the items B3.3 and B3.4, "reduction strategy", measured by our statements 5 and 6, and "adaptation strategy", measured by our items B3.7-B3.9. In addition, items 1, 2 and 10 are based on Meznar and $\mathrm{Nigh}^{42}$ and are intended to measure "political bridging strategy" by anticipating regulation and continuously tracking its development in order to have corporate compliance mechanisms in place by the time legislation is enacted, or even exceed compliance levels.

\footnotetext{
46 Thomas and McDaniel (1990, p. 306).

${ }^{47}$ Dutton and Jackson (1987).

${ }^{48}$ Jackson and Dutton (1988).

${ }^{49}$ Heavey et al. (2009, p. 1309).

${ }^{50}$ Fredrickson (1984); Fredrickson and Mitchell (1984).

51 Birnbaum (1985).

52 Engau and Hoffmann (2011b).

53 Hillman et al. (2004).
} 
B4 This measures the scope of adaptation to the respective solvency frameworks. Building on the work of Lant and Mezias ${ }^{54}$ we measure change in four critical organisational dimensions: business strategy, organisational structure, internal power distribution and internal control systems (see B4.2-B4.5). We have added changes to the overall business model as our first item (B4.1).

B5 Finally, B5 measures the specific sites of business model adaptation as a response to Solvency II/SST regulation based on ideas of Parker ${ }^{55}$ and Zott et al. ${ }^{56}$

\section{Results of factor analysis}

We apply a factor analysis with varimax rotation to examine dimensionality of measures and appropriateness of items. In Table 4, we provide the questions (measurement items) and the constructs on which they loaded, as well as their respective descriptions and interpretations. In addition, we report the Cronbach $\alpha$ 's for each resulting construct in the last column. Cronbach $\alpha$ 's quantify how well a set of items measures a uni-dimensional latent construct. A threshold of 0.6 is commonly seen as an acceptable reliability coefficient. ${ }^{57}$ All Cronbach $\alpha$ 's are well above this common threshold, with the exception of avoidance strategy $\alpha$ (see below).

Factor analyses mostly confirm our hypotheses. Most of the developed question items load on the hypothesised, underlying constructs. Only our results for perceived impact of Solvency II/SST (survey questions in groups A1 and A2) and the management of uncertainty about Solvency II/SST (survey questions B3) require more attention, as the factor analysis' solution provides a finer-grained picture. As can be seen from Table 4, our factor analysis' results point to three different constructs for the perceived impact. First, what we call "magnitude" measures the perceived level of new regulation's impact (item A1.1), which is distinct from the regulation's "scope", on which our item A1.3 together with items A2.1-A2.6 load. In addition, we find a third construct, which we label, "scope diversity", on which the two items A1.2 and A1.4 load. It includes two aspects of diversity: the number of regulatory agencies to be dealt with and the number of countries with different solvency regulations to be considered.

The ten items developed in Part B3 to measure the way uncertainty about Solvency II/SST is managed do not load fully consistently with prior studies' results. Again, our results are finer-grained and show that adaptation behaviours in the insurance industry do not necessarily occur in parallel. To account for that, we include four single-item adaptation measures: "postponing" (item B3.3), "joining forces" (item B3.8), "observing" (item B3.9) and "exceeding compliance" (item B3.10). In addition, three two-item constructs emerge in line with prior research: "political bridging", "reduction strategy" and "avoidance strategy". The latter's Cronbach $\alpha$ is only 0.417 , below the usual threshold. We take this caveat into account when interpreting our results. However, we believe "avoidance strategy" represents a relevant response

\footnotetext{
${ }^{54}$ Lant and Mezias (1992).

55 Parker (2001).

56 Zott et al. (2011).

${ }^{57}$ See, e.g. Hair et al. (2006, p. 102).
} 
Table 4 Description of the relevant constructs based on the survey

\begin{tabular}{|c|c|c|c|}
\hline Constructs & Description and interpretation & Questions & $\alpha$ \\
\hline \multicolumn{4}{|c|}{ Perceived impact of Solvency II/SST } \\
\hline Magnitude & Perceived level of impact & A1.1 & - \\
\hline Scope & $\begin{array}{l}\text { Perceived scope of solvency, for example, affecting large } \\
\text { part of activities, products/services, capital structure, } \\
\text { organisational structure, risk management, profitability, } \\
\text { overall business model }\end{array}$ & $\mathrm{A} 1.3, \mathrm{~A} 2.1-\mathrm{A} 2.6$ & 0.843 \\
\hline Scope diversity & $\begin{array}{l}\text { Perceived diversity in scope of solvency: number of } \\
\text { regulatory agencies to be dealt with, diversity of } \\
\text { solvency intensity across countries }\end{array}$ & A1.2, A1.4 & 0.747 \\
\hline Preparation time & Enough time to prepare for new regulation & A 3.1 & - \\
\hline Quickness of effects & Activities quickly affected by new regulation & A 3.2 & - \\
\hline Pace of change & Rapidly changing regulatory environment & A 3.3 & - \\
\hline Perceived certainty & $\begin{array}{l}\text { Perceived certainty about target state, political } \\
\text { consensus, specific measures, competence of regulators, } \\
\text { interdependence with other regulations, own incentives }\end{array}$ & A4.1-A4.6 & 0.775 \\
\hline Competitors & Certainty of major competitors' strategic responses & A4.7 & - \\
\hline Opportunity & $\begin{array}{l}\text { Perception of solvency as an opportunity (positive } \\
\text { implications, gaining) }\end{array}$ & A5.1-A5.3 & 0.850 \\
\hline Threat & $\begin{array}{l}\text { Perception of solvency as a threat (negative implications, } \\
\text { losing) }\end{array}$ & A5.4-A5.6 & 0.739 \\
\hline Capability & $\begin{array}{l}\text { Assessment of own capability to address solvency } \\
\text { regulation }\end{array}$ & A5.7 & - \\
\hline \multicolumn{4}{|c|}{ Strategic adaptation to Solvency II/SST } \\
\hline $\begin{array}{l}\text { Decision } \\
\text { comprehensiveness }\end{array}$ & $\begin{array}{l}\text { Comprehensiveness of decision-making with thorough } \\
\text { examination of threats/opportunities, technical reports, } \\
\text { possible responses' search, criteria development }\end{array}$ & B1.1-B1.6 & 0.885 \\
\hline Political activity & $\begin{array}{l}\text { Engagement in policy-making, impact information, } \\
\text { active attempt to reduce impact, individual campaigns, } \\
\text { trade associations }\end{array}$ & B2.1-B2.6 & 0.812 \\
\hline Political bridging & $\begin{array}{l}\text { Tracking and anticipating regulation to be ready for } \\
\text { compliance }\end{array}$ & B3.1-B3.2 & 0.681 \\
\hline Reduction strategy & Search for additional info, focus on critical issues & B3.5-B3.6 & 0.622 \\
\hline Avoidance strategy & $\begin{array}{l}\text { Shifting to unregulated markets, portfolio- } \\
\text { rearrangement for exposure reduction }\end{array}$ & B3.4, B3.7 & 0.417 \\
\hline Postponement & Postponement of strategic decision until more certainty & B3.3 & - \\
\hline Joined forces & $\begin{array}{l}\text { Joining forces with others, for example, suppliers, } \\
\text { customers, or competitors }\end{array}$ & B3.8 & - \\
\hline Observation & $\begin{array}{l}\text { Observation and following (if appropriate) of other } \\
\text { companies' activities }\end{array}$ & B3.9 & - \\
\hline Exceed compliance & Exceeding compliance levels for the new regulation & B3.10 & - \\
\hline Adaptation & Overall scope of adaptation (both internal and external) & B4.1-5 & 0.830 \\
\hline External adaptation & $\begin{array}{l}\text { External adaptation through, for example, product } \\
\text { portfolio, business strategy }\end{array}$ & B4.1-2 & 0.894 \\
\hline
\end{tabular}


Table 4 (continued)

\begin{tabular}{|c|c|c|c|}
\hline Constructs & Description and interpretation & Questions & $\alpha$ \\
\hline Internal adaptation & $\begin{array}{l}\text { Internal adaptation through, for example, } \\
\text { organisational structure, power distribution, control } \\
\text { systems }\end{array}$ & B4.3-5 & 0.714 \\
\hline $\begin{array}{l}\text { Product } \\
\text { diversification }\end{array}$ & Increase in product and service diversification & B5.1 & - \\
\hline $\begin{array}{l}\text { Geographical } \\
\text { diversification }\end{array}$ & Increase in geographical diversification & B5.2 & - \\
\hline Asset diversification & Increase in asset diversification & B5.3 & - \\
\hline Served customers & Increase in served customer segments & B5.4 & - \\
\hline In-house risks & Increase risks kept in-house & B5.5 & - \\
\hline Product pricing & Increase in product pricing & B5.6 & - \\
\hline
\end{tabular}

The validity of the different constructs is analysed through the coefficient of reliability Cronbach alpha, denoted by $\alpha$ and reported next to each construct.

strategy in our study context and thus we include it in our subsequent analyses. While the Cronbach $\alpha$ for our overall adaptation measure (items B4.1-B4.5) is more than satisfactory, our aim is to account for important differences in strategic adaptation. To do that, we differentiate between adaptation oriented towards the market, that is, "external adaptation" (items B4.1-B4.2, with Cronbach $\alpha$ of 0.894) and adaptation oriented towards the organisation, that is, "internal adaptation" (items B4.3-B4.5 with Cronbach $\alpha$ of 0.714 ).

\section{Survey results}

To analyse our data, we follow a three-step approach. First, we compare the mean values across the three groups, namely countries (providing a finer-grained distinction of the regulatory framework), business type and company size ("Differences by country, business type and company size"). Second, we assess these three groups' predictive power by individually regressing all perceived impact and strategic adaptation variables on the three groups. This enables us to determine their relative importance ("Determining the relative predictive role of the three grouping variables: Regulatory framework, business type and company size"). Third, while controlling for these three variables' influence, we use a second regression model to test the influence of six perceived solvency effects on (planned) management actions ("What drives strategic adaptation? The additional role of the perceived effects").

\section{Differences by country, business type and company size}

In this part, we are interested in understanding differences between countries, companies' business types and firm size with respect to several aspects of solvency regulation. Thus we compare the survey results in these three dimensions. 


\section{Switzerland vs Germany vs Austria}

With respect to country differences, we expect differences between Switzerland, where the new solvency regulation SST has already been implemented, and Germany and Austria, where Solvency II is still an ongoing process. Table 5 shows the descriptive results including mean values (column " $\mu$ ") and standard deviation (column " $\sigma$ ") per country and overall for each of the constructs and single items defined in Table 4.

Table 5 Descriptive statistics of the survey results by country

\begin{tabular}{|c|c|c|c|c|c|c|c|c|c|c|c|}
\hline \multirow[t]{2}{*}{ Constructs } & \multicolumn{3}{|c|}{ Switzerland } & \multicolumn{3}{|c|}{ Germany } & \multicolumn{3}{|c|}{ Austria } & \multicolumn{2}{|c|}{ Overall } \\
\hline & $\mu$ & $\sigma$ & sig. & $\mu$ & $\sigma$ & sig. & $\mu$ & $\sigma$ & sig. & $\mu$ & $\sigma$ \\
\hline \multicolumn{12}{|c|}{ Perceived impact of Solvency II/SST } \\
\hline Magnitude & 3.71 & $(1.16)$ & $\mathrm{B}$ & 4.37 & $(0.55)$ & A & 4.18 & $(0.85)$ & & 4.15 & $(0.86)$ \\
\hline Scope & 3.02 & $(0.83)$ & & 3.40 & $(0.70)$ & & 3.35 & $(0.60)$ & & 3.29 & $(0.71)$ \\
\hline Scope diversity & 2.94 & $(1.30)$ & $\mathrm{b}$ & 2.23 & $(1.14)$ & ac & 2.80 & $(0.98)$ & $\mathrm{b}$ & 2.59 & $(1.16)$ \\
\hline Preparation time & 3.65 & $(0.79)$ & $\mathrm{BC}$ & 2.29 & $(0.97)$ & Ac & 2.84 & $(1.19)$ & $\mathrm{Ab}$ & 2.79 & $(1.13)$ \\
\hline Quickness of effects & 3.06 & $(1.20)$ & & 3.37 & $(0.89)$ & & 3.02 & $(0.96)$ & & 3.19 & $(0.99)$ \\
\hline Pace of change & 3.47 & $(0.80)$ & $\mathrm{BC}$ & 3.94 & $(0.64)$ & A & 4.02 & $(0.76)$ & A & 3.85 & $(0.74)$ \\
\hline Perceived certainty & 2.97 & $(0.57)$ & B & 2.30 & $(0.57)$ & $\mathrm{AC}$ & 2.82 & $(0.50)$ & $\mathrm{B}$ & 2.63 & $(0.62)$ \\
\hline Competitors & 2.88 & $(0.62)$ & & 2.65 & $(0.71)$ & & 2.73 & $(0.70)$ & & 2.73 & $(0.68)$ \\
\hline Opportunity & 3.35 & $(0.88)$ & $\mathrm{c}$ & 2.96 & $(0.89)$ & & 2.86 & $(0.90)$ & $\mathrm{a}$ & 3.03 & $(0.90)$ \\
\hline Threat & 1.86 & $(0.64)$ & $\mathrm{B}$ & 2.35 & $(0.72)$ & Ac & 2.03 & $(0.67)$ & $\mathrm{b}$ & 2.13 & $(0.71)$ \\
\hline Capability & 4.12 & $(0.60)$ & B & 3.74 & $(0.63)$ & Ac & 4.05 & $(0.65)$ & $\mathrm{b}$ & 3.93 & $(0.64)$ \\
\hline \multicolumn{12}{|c|}{ Strategic adaptation to Solvency II/SST } \\
\hline $\begin{array}{l}\text { Decision } \\
\text { comprehensiveness }\end{array}$ & 3.50 & $(0.79)$ & & 3.39 & $(0.74)$ & & 3.20 & $(0.69)$ & & 3.36 & $(0.74)$ \\
\hline Political activity & 2.96 & $(1.16)$ & & 2.95 & $(0.84)$ & & 2.81 & $(0.90)$ & & 2.91 & $(0.93)$ \\
\hline Political bridging & 3.41 & $(0.83)$ & & 3.47 & $(0.61)$ & & 3.48 & $(0.70)$ & & 3.46 & $(0.69)$ \\
\hline Reduction strategy & 3.65 & $(0.72)$ & & 3.76 & $(0.74)$ & & 3.57 & $(0.56)$ & & 3.67 & $(0.68)$ \\
\hline Avoidance strategy & 1.82 & $(0.81)$ & & 1.54 & $(0.63)$ & & 1.48 & $(0.70)$ & & 1.59 & $(0.70)$ \\
\hline Postponement & 2.59 & $(0.94)$ & & 2.68 & $(1.04)$ & & 2.34 & $(1.04)$ & & 2.55 & $(1.01)$ \\
\hline Joined forces & 2.81 & $(1.17)$ & & 2.24 & $(0.92)$ & & 2.55 & $(1.23)$ & & 2.47 & $(1.09)$ \\
\hline Observation & 3.19 & $(0.75)$ & & 3.26 & $(0.83)$ & & 3.39 & $(0.69)$ & & 3.28 & $(0.76)$ \\
\hline Exceed compliance & 3.31 & $(1.08)$ & $\mathrm{bC}$ & 2.60 & $(1.34)$ & $\mathrm{a}$ & 2.48 & $(0.79)$ & A & 2.72 & $(1.16)$ \\
\hline Adaptation & 2.74 & $(0.81)$ & & 2.97 & $(0.90)$ & & 3.10 & $(0.62)$ & & 2.96 & $(0.80)$ \\
\hline External adaptation & 2.69 & $(1.11)$ & & 2.70 & $(1.12)$ & & 2.61 & $(1.07)$ & & 2.67 & $(1.09)$ \\
\hline Internal adaptation & 2.77 & $(0.72)$ & $\mathrm{C}$ & 3.15 & $(0.87)$ & & 3.43 & $(0.50)$ & A & 3.15 & $(0.76)$ \\
\hline Product diversification & 3.33 & $(0.72)$ & & 3.25 & $(1.02)$ & & 3.29 & $(0.72)$ & & 3.28 & $(0.86)$ \\
\hline $\begin{array}{l}\text { Geographical } \\
\text { diversification }\end{array}$ & 2.80 & $(0.56)$ & & 2.73 & $(1.14)$ & & 2.86 & $(0.85)$ & & 2.79 & $(0.94)$ \\
\hline Asset diversification & 3.31 & $(0.87)$ & & 3.55 & $(0.77)$ & & 3.45 & $(0.86)$ & & 3.46 & $(0.82)$ \\
\hline Served customers & 3.25 & $(0.68)$ & & 3.08 & $(0.67)$ & & 3.26 & $(0.62)$ & & 3.18 & $(0.66)$ \\
\hline In-house risks & 3.13 & $(0.64)$ & & 2.85 & $(0.71)$ & & 3.00 & $(0.71)$ & & 2.96 & $(0.69)$ \\
\hline Product pricing & 3.69 & $(0.70)$ & B & 3.20 & $(0.61)$ & Ac & 3.52 & $(0.60)$ & $\mathrm{b}$ & 3.42 & $(0.65)$ \\
\hline
\end{tabular}

Mean $\mu$, standard deviation $\sigma$ and significant differences (sig.) are presented for all constructs. For each country and construct, the first number represents the average rating and the second number, in parentheses, the standard deviation. The letters denote pairwise significant differences, where A stands for Switzerland, B for Germany and C for Austria. Lowercase letters denote significance at the 10 per cent level, uppercase letters the 5 per cent level. 
Significant differences between pairs of countries are reported next to the descriptive results (column "sig."). The letters stand for the countries Switzerland (A), Germany (B) and Austria (C). Lowercase letters denote a significant difference at the 10 per cent level, uppercase letters at the 5 per cent level.

The perceived magnitude of the solvency framework is (as expected) lowest in Switzerland. German insurers envisage a significantly higher magnitude of regulation. As most of the Swiss insurance firms have to deal with European regulatory settings in addition to SST, they perceive the scope to be more diverse than do German firms. Also, Austrian firms perceive the diversity of solvency intensity and the number of regulatory agencies they have to deal with as being greater than do their German competitors. Swiss firms also diverge significantly from the Solvency II countries in terms of preparation time and perceived pace of regulatory changes. German and Austrian firms predominantly say they do not have enough time to prepare for new regulation and perceive the regulatory environment to be changing (too) rapidly. Thus, the early adoption of SST requirements, perceived as an unfair competitive disadvantage by some Swiss insurers, seems to have prepared Swiss insurers for any additional requirements. They are also the most certain concerning all related aspects of solvency regulation, its envisaged outcome, political consensus, specific measures, interdependence with other regulations and the incentives created. They also have more faith in the competence of the regulator(s) to implement Solvency II. Solvencyrelated uncertainty is highest among German insurance firms. Surprisingly, this also differs significantly from Austrian firms, which perceive uncertainty in a similar way to Swiss firms. However, it should be noted that even for Swiss firms, mean certainty assessment is 2.97 , that is, relatively low on a scale from 1 to 5 . Thus, uncertainty in the industry remains at high levels. Swiss insurance firms are most optimistic with respect to solvency regulation. They mostly attach positive implications to it, perceive no threat of losing anything and believe they have the organisational capabilities to exploit the opportunities presented. That contrasts starkly to German firms, which perceive themselves as lacking important capabilities to address solvency regulation, which poses a real threat to some of the firms. ${ }^{58}$ Austrian firms, in contrast, are relatively relaxed or even indifferent, as they predominantly expect neither positive nor negative implications and are quite confident about their own ability to deal with any changes. The unexpected neutral assessment of Austrian firms may be explained by the low proportion of life and large insurers in our Austrian sample compared with the German sample (however, we will see later that business type and company size do not significantly influence these variables). Decision-making comprehensiveness and political activity do not differ significantly between the countries. Swiss firms plan to exceed compliance levels by significantly more than their German and especially their Austrian peers. Regarding adaptation needs in response to Solvency II/SST, it can be seen that there is a difference only with respect to internal adaptation. Swiss firms have less need to adapt their organisational structure, power distribution or control systems (they may have done so in the past already). These differences are

\footnotetext{
${ }^{58}$ This contrasts with findings in QIS5 that reported that participants feel well prepared for Solvency II or even ahead in their preparations (EIOPA, 2011, p. 12).
} 
more pronounced (and significant) compared with the Austrian insurers, which plan the most internal adaptation. Austrian firms want to adjust both their internal organisational structures (by creating new divisions or shifting functions between divisions), and their internal power distribution (by changes in the functional backgrounds of their top management teams). Of the various sites of adaptation, only product pricing differs significantly between countries. German insurers plan significantly lower price increases than Swiss firms or Austrian firms.

In sum, we observe that there are differences in some dimensions between Swiss insurance firms already forced to comply with SST and German/Austrian insurance firms awaiting the new solvency regulations. Surprisingly, however, these differences are not consistently aligned. Only in the perceived preparation time and pace of change and the anticipated willingness to exceed required compliance are the differences consistent between Switzerland, on the one hand, and Germany and Austria on the other. Overall, Switzerland contrasts more strongly with Germany (nine significant differences) than with Austria (five significant differences). Germany also differs significantly from Austria in six dimensions. These differences consistently show that Austrian firms perceive themselves as less concerned or as more confident than German firms. It is an open question - not addressed in this analysis - whether that is a realistic self-perception or whether they have a false sense of security. Differences in our sample composition (see Table 1), differences in the market size (Germany's primary life and non-life insurance market with about $€ 180$ billion premium volume is about ten times larger than Austria's insurance market valued at $€ 19$ billion) and differences in the current regulatory environment between the two countries may account for this. Further factors that explain greater concerns in Germany may include the larger absolute size of insurance companies, the more intense public discussion and greater public awareness of the regulatory reforms, accompanied by a stronger degree of professionalisation and the incidence of internal vs external solvency models (strongly varying among countries).

\section{Life vs non-life companies}

In Table 6 we report the descriptive statistics for the life and non-life business lines as well as for large and small companies. The values represent the overall mean assessment over all three countries. For each pair of values (life/non-life, large/small) we report whenever the difference is significant (column "sig."). Extensive statistics for the different countries are reported in Tables A1 and A2.

In line with our expectations, life insurance firms perceive the scope of solvency regulation to be significantly larger than do non-life insurance firms. They are also less certain about the regulatory process and its final result in terms of detailed regulatory requirements. Consequently, life insurance firms see greater potential threats and opportunities arising from Solvency II/SST, prepare more detailed reports on possible impacts on their firm and search extensively for possible solutions, for which actions and clear selection criteria are developed. Life insurers are also more likely to engage in a broad range of political activities in an attempt to reduce the new regulations' (negative) impact. Final strategic decisions are more likely to be postponed until more certainty is achieved. Finally, and as a predominant characteristic, we find that life 
Table 6 Overall statistics by business type and company size

\begin{tabular}{|c|c|c|c|c|c|c|}
\hline Constructs & Life & Non-life & sig. & Large & Small & sig. \\
\hline \multicolumn{7}{|c|}{ Perceived impact of Solvency II/SST } \\
\hline Magnitude & 4.19 & 4.13 & & 4.31 & 3.99 & \\
\hline Scope & 3.56 & 3.12 & $* *$ & 3.43 & 3.16 & \\
\hline Scope diversity & 2.67 & 2.53 & & 2.73 & 2.44 & \\
\hline Preparation time & 2.67 & 2.87 & & 2.60 & 2.99 & \\
\hline Quickness of effects & 3.39 & 3.06 & & 3.24 & 3.13 & \\
\hline Pace of change & 3.87 & 3.84 & & 3.84 & 3.86 & \\
\hline Perceived certainty & 2.47 & 2.73 & $*$ & 2.54 & 2.72 & \\
\hline Competitors & 2.63 & 2.79 & & 2.76 & 2.70 & \\
\hline Opportunity & 3.17 & 2.94 & & 3.23 & 2.82 & $*$ \\
\hline Threat & 2.27 & 2.05 & & 2.17 & 2.10 & \\
\hline Capability & 3.81 & 4.00 & & 3.86 & 4.00 & \\
\hline \multicolumn{7}{|c|}{ Strategic adaptation to Solvency II/SST } \\
\hline Decision comprehensiveness & 3.57 & 3.22 & $* *$ & 3.59 & 3.12 & $* * *$ \\
\hline Political activity & 3.19 & 2.73 & $* *$ & 3.23 & 2.58 & $* * *$ \\
\hline Political bridging & 3.53 & 3.41 & & 3.61 & 3.31 & $*$ \\
\hline Reduction strategy & 3.79 & 3.60 & & 3.82 & 3.52 & $*$ \\
\hline Avoidance strategy & 1.75 & 1.49 & & 1.76 & 1.41 & $* *$ \\
\hline Postponement & 2.80 & 2.40 & $*$ & 2.70 & 2.40 & \\
\hline Joined forces & 2.58 & 2.41 & & 2.74 & 2.21 & $* *$ \\
\hline Observation & 3.29 & 3.28 & & 3.28 & 3.29 & \\
\hline Exceed compliance & 2.52 & 2.85 & & 3.01 & 2.44 & $* *$ \\
\hline Adaptation & 3.31 & 2.75 & $* * *$ & 3.08 & 2.85 & \\
\hline External adaptation & 3.35 & 2.26 & $* * *$ & 3.00 & 2.35 & $* *$ \\
\hline Internal adaptation & 3.28 & 3.07 & & 3.13 & 3.18 & \\
\hline Product diversification & 3.90 & 2.90 & $* * *$ & 3.51 & 3.03 & $* *$ \\
\hline Geographical diversification & 2.44 & 3.00 & $* *$ & 2.62 & 2.97 & \\
\hline Asset diversification & 3.62 & 3.37 & & 3.51 & 3.41 & \\
\hline Served customers & 3.25 & 3.13 & & 3.27 & 3.08 & \\
\hline In-house risks & 2.94 & 2.98 & & 2.99 & 2.94 & \\
\hline Product pricing & 3.69 & 3.24 & $* * *$ & 3.40 & 3.44 & \\
\hline
\end{tabular}

Mean ratings and significant differences (sig.) for life and non-life, and for large and small companies are presented. Numbers represent the average rating and asterisks denote the significant differences among the categories considered. $* * *$ and $* * *$ denote significance at the 10,5 and 1 per cent levels, respectively.

insurers are more forced to adapt than insurers with relatively less or no life-business. This significant difference is confined to market-related adaptation (external adaptation), such as changing their business strategy and product/service portfolio. It does not apply to internal adaptation. More specifically, life insurance companies are increasing their product diversification and product pricing (the latter means are being used especially by Austrian life insurers; see Table A1 for details), while they are more cautious with respect to geographical diversification.

\section{Large vs small companies}

Table 6 reports the survey results for large and small companies. Details by country can be found in Table A2. While larger firms' assessment of the perceived impact 
variables is consistently higher (e.g. stronger scope, less certainty), differences between small and large firms are not significant. The only significant difference relates to opportunity perception. In contrast to small firms, large firms perceive a higher upside potential in solvency regulation that may provide them with positive future effects and a higher probability of gain. This could be due to greater confidence on the part of large firms that they can adapt to new regulations as well as their perception that small firms will be more challenged, which could give large firms a competitive advantage as the new regulations are implemented. In fact, large Swiss insurance firms, for which the additional compliance requirements under Solvency II are higher compared with their smaller, local competitors, perceive a significantly greater magnitude and diversity of solvency regulation (see Table A2). Unsurprisingly, large firms, building on their extensive financial and human resources, more thoroughly analyse all solvency-related threats and opportunities to prepare scenarios and potential alternative response strategies. To do that, they more extensively track and anticipate regulation so as to be ready for compliance (political bridging). They want to voluntarily exceed regulatory requirements more than their small competitors. Larger firms are also more focused on the critical issues of solvency regulation (reduction strategy). They are consistently more politically involved and plan to adapt more extensively by several means: by joining forces with others (e.g. suppliers, customers or competitors), and by adapting their external business strategy and product offerings, which they want to further diversify. Large German insurers additionally want to change their customer base more significantly in response to Solvency II compared with smaller German firms.

Overall, business type and company size are the more important factors affecting differences in strategic adaptation to Solvency II/SST. Firm size in particular drives political activities. With respect to the perceived impact of Solvency II, it is clear that (with the exception of the opportunity perception) no significant differences between small and large firms exist.

\section{Determining the relative predictive role of the three grouping variables: Regulatory} framework, business type and company size

In addition to the "within group" differences reported in the section "Differences by country, business type and company size", we are interested in the relative predictive power of the grouping variables considered (country, business type, company size). In order to better understand their relative importance, we individually regress all perceived impact and all strategic adaptation variables on these three groups in the same model. This conservative approach helps us to identify robust influences of one variable while controlling for the other two.

Table 7 reports the results of our regression analyses. In the table's first column the constructs and items that act as dependent variables in the individual regression analyses are listed. For each regression model we report the standardised beta coefficients (column " $\beta$ ") and significance levels (column "sig.") for the three independent variables, which we denote by "regulation", "size (log)" and "business type". The variable regulation represents the planned regulatory environment and is used as a dummy variable taking the value "1" for Solvency II countries, that is, 
Table 7 Regression statistics on regulatory framework, size and business type

\begin{tabular}{|c|c|c|c|c|c|c|c|}
\hline \multirow[t]{2}{*}{ Constructs } & \multicolumn{2}{|c|}{ Regulation } & \multicolumn{2}{|c|}{ Size (log) } & \multicolumn{2}{|c|}{ Business type } & \multirow[t]{2}{*}{ Adjusted $R^{2}$} \\
\hline & $\beta$ & sig. & $\beta$ & sig. & $\beta$ & sig. & \\
\hline \multicolumn{8}{|c|}{ Perceived impact of Solvency II/SST } \\
\hline Magnitude & 0.28 & $* *$ & 0.23 & $*$ & -0.03 & & 0.09 \\
\hline Scope & 0.22 & $*$ & 0.03 & & 0.31 & $* *$ & 0.12 \\
\hline Scope diversity & -0.21 & $*$ & 0.35 & $* *$ & -0.19 & & 0.08 \\
\hline Preparation time & -0.42 & $* * *$ & -0.09 & & -0.06 & & 0.17 \\
\hline Quickness of effects & 0.07 & & 0.02 & & 0.15 & & -0.01 \\
\hline Pace of change & 0.28 & $* *$ & 0.09 & & 0.01 & & 0.05 \\
\hline Perceived certainty & -0.32 & $* * *$ & -0.02 & & -0.18 & & 0.10 \\
\hline Competitors & -0.15 & & 0.25 & $*$ & -0.35 & $* *$ & 0.07 \\
\hline Opportunity & -0.23 & $*$ & 0.23 & $*$ & 0.11 & & 0.09 \\
\hline Threat & 0.22 & $*$ & -0.05 & & 0.19 & & 0.04 \\
\hline Capability & -0.16 & & -0.07 & & -0.04 & & -0.01 \\
\hline \multicolumn{8}{|c|}{ Strategic adaptation to Solvency II/SST } \\
\hline Decision comprehensiveness & -0.14 & & 0.36 & $* * *$ & 0.08 & & 0.14 \\
\hline Political activity & -0.07 & & 0.45 & $* * *$ & 0.00 & & 0.17 \\
\hline Political bridging & 0.01 & & 0.36 & $* * *$ & -0.03 & & 0.08 \\
\hline Reduction strategy & 0.01 & & 0.14 & & 0.12 & & 0.01 \\
\hline Avoidance strategy & -0.21 & $*$ & 0.24 & $*$ & 0.04 & & 0.06 \\
\hline Postponement & -0.03 & & 0.12 & & 0.19 & & 0.03 \\
\hline Joined forces & -0.19 & & 0.14 & & 0.06 & & 0.02 \\
\hline Observation & 0.07 & & 0.05 & & -0.09 & & -0.03 \\
\hline Exceed compliance & -0.33 & $* * *$ & 0.41 & $* * *$ & -0.33 & $* *$ & 0.19 \\
\hline Adaptation & 0.15 & & -0.05 & & 0.34 & $* *$ & 0.09 \\
\hline External adaptation & -0.03 & & 0.11 & & 0.38 & $* * *$ & 0.16 \\
\hline Internal adaptation & 0.30 & $* *$ & -0.20 & & 0.23 & $*$ & 0.09 \\
\hline Product diversification & -0.05 & & 0.16 & & 0.46 & $* * *$ & 0.27 \\
\hline Geographical diversification & -0.01 & & -0.04 & & -0.26 & $*$ & 0.03 \\
\hline Asset diversification & 0.11 & & 0.03 & & 0.15 & & -0.01 \\
\hline Served customers & -0.07 & & 0.17 & & -0.06 & & -0.02 \\
\hline In-house risks & -0.12 & & -0.16 & & 0.11 & & -0.01 \\
\hline Product pricing & -0.20 & $*$ & -0.27 & $* *$ & 0.44 & $* * *$ & 0.16 \\
\hline
\end{tabular}

Standardised beta coefficients $\beta$ and significance (sig.) are presented for all constructs with respect to the variables regulation framework (Solvency II, i.e. Germany and Austria, vs SST, i.e. Switzerland), size (log of total premium volume) and business type (ratio life premiums to total premiums). *, **, and *** denote significance ( $t$-test) at the 10,5 and 1 per cent levels respectively.

Germany and Austria, and the value "0" for the SST country, that is, Switzerland. The company size (see size $(\log )$ ) is measured as the natural logarithm of a firm's total premium volume in 2010 as reported by the national regulatory bodies. Finally, the variable business type is measured as the ratio of a firm's life premiums to its total premium volume. For each model, we report the adjusted $R^{2}$ (see the last column of Table 7).

The first line shows the three variables' influence on the perceived magnitude of solvency regulation. 
This level is higher for Solvency II countries and the larger firms. Regarding the scope of solvency regulation, the proportion of life insurance business in a firm's revenue portfolio is the most relevant predictor. The higher this is, the more their business activities, products/services, capital structure, organisational structure, risk management, profitability and overall business model are affected. In addition, Swiss firms perceive the regulation to have less scope. Regulation scope diversity increases with firm size and is higher for Swiss firms. Preparation time was higher for Swiss firms, which also perceive pace of change to be lower (recall that SST has already been implemented, in summer 2011). The regulatory setting is also the only significant driver of (un)certainty. While firm size and business line do not have an influence, Swiss firms are significantly more certain about solvency than their German and Austrian competitors. Consistently, regulation territory (SST vs Solvency II), that is, the framework being in force or merely in preparation, influences the opportunity and threat perception. For Swiss firms, this results in a stronger opportunity and a weaker threat perception. In addition, the larger an insurance firm, the stronger its opportunity perception. The certainty with which competitors' response behaviour is predicted increases with firm size and the size of non-life business activity. Thus, small life insurers are most uncertain about industry peers', and especially industry leaders', behaviour. Decision comprehensiveness, political activity and political bridging are significantly and positively (and exclusively) influenced by firm size. Reduction, postponement, joining forces and observation strategies are not significantly influenced by any of the three independent variables. Swiss-based and larger firms are more likely to avoid regulation by shifting part of their business activities to unregulated markets and restructuring their portfolios to reduce exposure. At the same time, precisely these firms attempt to exceed compliance requirements (at least for their remaining activities which fall under regulatory governance), as do non-life insurance firms. In line with our results from the mean comparison (see the section "Differences by country, business type and company size"), Swiss firms are less likely to adapt (or have already adapted in recent years) their internal organisation structure, processes and control systems to deal with new solvency regulations. The difference observed previously between large and small insurers in terms of external adaptation cannot be observed at a statistically significant level in our regression results. It may be being overshadowed by the strong influence of the business line. The latter clearly shows that the larger the life business portfolio of an insurer, the more likely it is to adapt extensively, both internally and externally, by changing its business strategy and products/services portfolio. Products are more likely to be diversified and prices to be further increased, while they refrain from any increase in their geographical footprint. It is notable that any increases in product diversification can be explained to a degree of 27 per cent by the size of life in relation to non-life business. Price increases are less likely for German/Austrian firms and smaller companies. With respect to three other sites of adaptation, changes to asset diversification, customer segments served, and risks kept in-house vs sourced out to external partners, the three variables have no explanatory power.

In sum, the business line has the least explanatory power with respect to the perceived impact of solvency regulation (with the important exception of overall scope). SST vs Solvency II predicts most of the variance in these dependent variables 
(eight significant links), followed by firm size (four significant links). The three grouping variables explain around 5-17 per cent of the observed variance in the perceived impact, with no predictive power for perceived quickness of effects or, surprisingly, firms' capabilities. For internal decision-making and political strategies, firm size is the key driver and explains up to 19 per cent of total variance. To understand real strategic actions in response to Solvency II, the weight of the two business lines is important. Regression results show that insurance firms with a higher proportion of life business are more likely to adapt to Solvency II. They do that by combining both externally oriented with internally oriented actions. While controlling for the influence of the regulatory environment, firms' size and life and non-life business lines, our objective is to further test in a second regression model the six perceived solvency effects' influence on (planned) management actions (see the section "What drives strategic adaptation? The additional role of the perceived effects").

\section{What drives strategic adaptation? The additional role of the perceived effects}

In the preceding sections, we saw in our "means comparison exercise between groups" ("Differences by country, business type and company size") that adaptation differs between countries (internal adaptation), between life and non-life business lines (adaptation overall and external adaptation) and depending on firm size (external adaptation). Our regression results in the section ("Determining the relative predictive role of the three grouping variables: Regulatory framework, business type and company size") show that business line is the best predictor of adaptation, especially for external adaptation where it explains 16 per cent of variance, and that regulatory environment additionally explains observed variance in internal adaptation. In the sequel we will apply the label "model 1" to the regression analyses done in the section ("Determining the relative predictive role of the three grouping variables: Regulatory framework, business type and company size") and reported in Table 7.

In this section, our aim is to understand whether the perceptions of solvency effects (see the survey questions A2.1-A2.6) additionally explain variance in (planned) management actions. To understand the effects of Solvency II/SST on firms' business activities, we first asked the firms' representatives to assess the extent of expected effects on their products and services (A2.1), capital structure (A2.2), organisational structures and internal processes (A2.3), risk management (A2.4), profitability (A2.5), and overall business model (A2.6). To test that in a conservative manner, we ran a second regression model for the individual items in the scope of strategic adaptation (B.4) and sites of business model adaptation (B.5) topic groups as dependent variables after controlling in model 1 for the three variables of regulation, size and business type. The results are displayed in Table 8 in which we report, in addition to standardised beta coefficients and significance level, the adjusted $R^{2}$ for the new model, called "model 2", as well as the difference of model 2's adjusted $R^{2}$ vs the adjusted $R^{2}$ observed in model 1 (see Table 7). This difference in adjusted $R^{2}$ is denoted by $\Delta$ and reported in the last column of Table 8 .

In both topic groups (scope of strategic adaptation and sites of business model adaptation) we consider several dimensions (dependent variables) in our analysis. We break down the scope of strategic adaptation to Solvency II into five dimensions: 
Table 8 Additional regression statistics on solvency effects

\begin{tabular}{|c|c|c|c|c|c|c|c|c|c|c|c|c|}
\hline \multirow{3}{*}{ Management actions } & \multicolumn{11}{|c|}{ Perceived effects of solvency } & \multirow[b]{2}{*}{$\begin{array}{c}\text { Adjusted } \\
R^{2}\end{array}$} \\
\hline & \multicolumn{2}{|c|}{$\begin{array}{l}\text { Products } \\
\text { and } \\
\text { services }\end{array}$} & \multicolumn{2}{|c|}{$\begin{array}{l}\text { Capital } \\
\text { structure }\end{array}$} & \multicolumn{2}{|c|}{$\begin{array}{c}\text { Organisation } \\
\& \text { processes }\end{array}$} & \multicolumn{2}{|c|}{$\begin{array}{c}\text { Risk } \\
\text { management }\end{array}$} & \multicolumn{3}{|c|}{$\begin{array}{r}\text { Profitability Business } \\
\text { model }\end{array}$} & \\
\hline & $\beta$ & sig. & $\beta s$ & sig. & $\beta$ & sig. & $\beta$ & sig. & $\beta$ & sig. & $\beta$ sig. & Value $\Delta$ \\
\hline \multicolumn{13}{|l|}{ Scope of strategic adaptation } \\
\hline Business model & 0.24 & $*$ & 0.11 & & -0.01 & & 0.00 & & -0.17 & & $0.51 * * *$ & 0.560 .38 \\
\hline Business strategy & 0.30 & $* *$ & -0.02 & & -0.15 & & -0.05 & & -0.16 & & $0.65 * * *$ & $0.50 \quad 0.39$ \\
\hline Organisational structure & 0.23 & & 0.02 & & 0.34 & $* *$ & -0.09 & & -0.26 & $*$ & 0.27 & 0.320 .22 \\
\hline Internal power distribution & 0.39 & $* *$ & -0.21 & * & 0.15 & & -0.11 & & 0.19 & & 0.12 & 0.390 .28 \\
\hline Internal control system & 0.04 & & 0.25 & * & 0.08 & & 0.22 & $*$ & 0.21 & & 0.11 & 0.360 .38 \\
\hline \multicolumn{13}{|c|}{ Sites of business model adaptation } \\
\hline Product diversification & 0.32 & $*$ & -0.03 & & -0.09 & & 0.07 & & -0.08 & & -0.04 & $0.25-0.02$ \\
\hline Geographical diversification & 0.25 & & -0.16 & & -0.12 & & -0.09 & & 0.13 & & 0.15 & $0.00-0.03$ \\
\hline Asset diversification & 0.32 & & 0.38 & $* *$ & 0.01 & & -0.05 & & -0.09 & & -0.12 & 0.120 .13 \\
\hline Served customers & 0.59 & $* * *$ & -0.17 & & -0.13 & & 0.10 & & 0.13 & & -0.13 & 0.070 .09 \\
\hline In-house risks & -0.03 & & 0.04 & & -0.14 & & 0.11 & & -0.43 & $* * *$ & $0.49 * *$ & 0.100 .10 \\
\hline Product pricing & 0.51 & $* * *$ & -0.03 & & -0.24 & $*$ & 0.12 & & -0.08 & & 0.22 & $0.34 \quad 0.18$ \\
\hline
\end{tabular}

Standardised beta coefficients $\beta$ and significance (sig.) are presented for all management actions (scope of adaption and sites of business model adaptation, see survey questions B4.1-B4.5 and B5.1-B5.6) with respect to additional variables added to those presented in Table 7 (regulation framework, size and business type). The additional independent variables considered are the perceived effects of solvency regulation (see survey questions A2.1-A2.6). *** and *** denote significance ( $t$-test) at the 10,5 and 1 per cent levels respectively. The reported values for the adjusted $R^{2}$ correspond to the regression model including the three variables from the model in Table 7 and the additional six independent variables from the present table. $\Delta$ refers to the difference in adjusted $R^{2}$ when comparing this augmented model with the first regression model (see adjusted $R^{2}$ in Table 7).

business model, business strategy, organisational structure, internal power distribution and internal control system. The two first dimensions (business model and strategy) are jointly reported in Table 7 under the aggregated construct "external adaptation", whereas the three last items in the scope of strategic adaptation section are aggregated under "internal adaptation" in Table 7. Furthermore, the sites of business model adaptation are differentiated along six key dimensions: product, geographical and asset diversification as well as served customer segments, in-house risks and product pricing changes. The regression model results are reported individually for each of the 11 dependent variables in Table 8 .

On average, the more an insurance company perceives solvency regulation to affect its current product and service portfolio, the more likely it is to adapt its business model and business strategy, that is, its external market approach. More specifically, this is commonly done by increasing product diversification and/or pricing, and by serving additional customers. In addition, these insurers are also more likely to adapt their internal power distribution, that is, change the top management team's composition. They tend to promote or hire top managers with a strong orientation 
towards and capabilities in risk management, who may also have different industry backgrounds (especially banking). Insurers that perceive their capital structure to be significantly affected by new solvency regulation are more likely to increase their asset diversification. In addition, they differ, on average, in their internal adaptation behaviour. Specifically, they are less likely to change the internal power distribution but more likely to alter their existing control systems (e.g. their management information systems). In line with our predictions, we find insurance firms that perceive internal aspects to be affected by solvency regulation are more likely to make internal (instead of external) adaptations. When firms' organisational structures and internal processes are significantly affected, they are more active in trying to adapt their organisations' internal structure, for example by shifting functions between divisions or creating new divisions. Their internal orientation is also observable in negative (but not significant) coefficients for external market adaptations and a significantly lower likelihood of increasing their product pricing. Similarly, a higher risk management impact promotes internal adaptation of existing control systems, especially, of risk management systems. Insurance firms in which profitability (e.g. combined ratio) is significantly affected by solvency regulation are more likely to outsource their risks to external partners in order to reduce the risk remaining inhouse. In addition, they avoid any organisational adaptations, which usually come with significant costs. Finally, the more the insurer's overall business model is affected by Solvency II/the SST, the more they attempt to adapt externally by making changes to both their business strategy and their product portfolio. Additionally, these firms are, on average, increasing their internally kept risk. ${ }^{59}$

It can be seen that the scope of both external and internal adaptation means is well explained by the six perceived effects of solvency regulation on a firm. We additionally explain between 22 and 39 per cent of the variance, resulting in a reasonably robust model. For example, we are able to explain more than 50 per cent of all adaptations to business models in the insurance industry. While external adaptations, both of business strategy and business model, are consistently explained by all perceived impacts on market offerings (the impact on products and services as well as on the current business model have a similar positive influence), the explanation of internal adaptations is a little more complex. For example, predictions of expected internal organisational structure changes in insurance companies depend on two perceptions: the perceived impact on internal processes (positive link) and the firm's profitability (negative link). In insurance firms that perceive simultaneously a significant need to adapt their internal structures and profitability challenges, the two opposing influences will make their internal adaptation less predictable. Additionally, explained variances for the sites of business model adaption are lower, but still explain up to 18 per cent for product pricing. However, we have no additional explanation for product diversification in addition to country, size and

\footnotetext{
${ }^{59}$ Overall, the share of explained variance (see the adjusted $R^{2}$ ) in the considered models is relatively low. This suggests that there are a number of other variables affecting firms' perceived impact and strategic adaptation beyond the three explanatory variables used. Other variables could include several business key performance indicators (e.g. current solvency ratio, profitability ratios) and further information about firms' organisation and historical performance and activities.
} 
business line. Variation in (planned) geographical diversification can neither be explained by the variables in model 1 nor by those in model 2 . It seems to be unaffected by solvency regulation.

\section{Discussion of main results}

Four research questions guided our study. First, we were interested in whether there are significant differences between Swiss insurance companies already forced to comply with SST on the one hand, and German and Austrian insurance companies awaiting the new Solvency II regulations on the other. The expected differences in the perception of solvency regulation are partly confirmed by our results: Swiss firms perceive the pace of change to be significantly lower and the resulting preparation time for themselves as tight but not as much so as their German and Austrian competitors do. At the same time, our results show unexpected differences within the Solvency II countries: Swiss firms differ only compared with one of the two Solvency countries (the greater contrast being with Germany), and German firms differ from their Austrian competitors. Overall, Austrian firms are found to be less concerned about upcoming regulations. Thus, one should not assume that Solvency II countries are a homogenous group. Future research should extend the geographical scope of this study to include other European countries with diverse historical regulatory regimes. We have presented two contradictory perspectives for the expected differences in strategic adaptation. Our results show parallel behaviour in terms of external adaptation, lending support to our argument that both regulatory frameworks build on similar ideas and thus induce comparable market adaptation, but divergent behaviour with respect to internal adaptation. It seems that some Swiss firms have used their lead time to align their internal processes and systems with the new regulatory environment already. German and especially Austrian firms stress a higher need to do so in the future.

Second, we were interested in the role of a company's dominant business line as a predictor of differences in perception and action. Our results lend support to the argument that life insurance firms are more affected than non-life insurance firms. Life insurers perceive the scope of solvency regulation to be greater. They feel more uncertain about all dimensions of this regulatory change. Differences between life and non-life are even more pronounced in terms of strategic adaption. Life insurers compared with non-life insurers are more politically active and try to postpone any changes for as long as possible. In the end, however, they are forced to adapt their market offerings more significantly - they plan to increase their product diversification and also their product pricing.

Third, we wanted to investigate the role of insurance firm size as an (additional) influencing factor, expecting that large insurers have, on average, an advantage as they bear the cost and complexity of optimising capital models. Our finding that large firms see more opportunities arising from new regulation lends some support to our hypothesis. At the same time, however, larger insurance firms perceive a greater magnitude of regulation and, in particular, have to cope with a higher degree of regulatory diversity between the countries they are active in. In line with our argument that larger firms have more resources as well as stronger political relationships to build 
on, we found that they analysed the new situation more extensively and tried to exert an influence by actively engaging in politics.

Fourth, we have focused on the role of firms' perception of solvency regulation's impact on their (planned) strategic adaptation. The preceding section ("What drives strategic adaptation? The additional role of the perceived effects") has clearly shown that these different perceived effects do have a significant and distinct additional explanatory power that deserves future research attention. Future research should especially focus on analysing the influence of these perceptions on real (in contrast to intended) strategic adaptation.

The focus of our study was on implications for industry incumbents - the insurance firms themselves. Our results, however, also provide some evidence of potential implications for two other important stakeholder groups-industry regulators and customers.

New solvency regulation was driven by the aim of improving customer protection from company default. Consequently, customer protection is the predominant goal of the regulators. However, regulators also have to ensure that the insurance firms affected by new regulation know what is expected of them. The extremely low perceived "certainty" of all respondents about the new solvency regulation in general, and the perceived competence of the regulator in particular, is a worrying finding of our study. This industry-wide uncertainty is extremely pronounced in Germany, especially for the smaller players. There is a need to resolve those issues which remain open and to communicate the requirements openly. Regulators must ensure that all insurance firms comply satisfactorily with solvency regulation. This is a costly process, given the significant resource limitations (human and financial) of the regulators. Our findings may provide regulatory authorities with some cautionary evidence about which insurance firms' compliance they should primarily focus on. First, the Swiss Financial Market Authority (FINMA) has least cause for concern. According to our results, Swiss insurance firms want to be the best in terms of compliance. Second, all regulators should monitor the activities of smaller firms and of life insurers more closely. The relationship between uncertainty and willingness to exceed compliance is striking (i.e. the most uncertain small German firms are also the ones with the lowest mean value for exceeding compliance).

While the final goal of solvency regulation is better customer protection against insurers' default, our findings question whether the outcome for customers will be entirely positive. While they may benefit from larger insurance firms addressing a broader customer base, most insurers, and especially the smaller ones, plan to increase their pricing of products and services. The findings indicate in particular a price increase for life insurance products. It has to be noted that there can be an inherent trade-off between an insurance company's financial risk and its pricing. For example, holding more capital will increase a firm's capital costs, all other things being equal. Hence regulators need to consider this trade-off when they strengthen solvency requirements and whether the expected benefits from lower insolvency costs outweigh the associated higher costs of insurers' products and services. ${ }^{60}$

\footnotetext{
${ }^{60}$ See also Lorson et al. (2013).
} 


\section{Conclusion}

The starting point of our research was the current reforms of solvency regulation in Europe including the solvency test which has already been implemented and is in force in Switzerland, and the planned Solvency II regulations in the EU. By means of an industry survey, we studied the insurance companies' perception and assessment of the regulatory impact and their (planned) management actions. We focused on the perception of the impact, the effects and the uncertainty accompanying the reforms. We then considered the results in relation to the companies' strategic adaption to the new frameworks. For this, we looked at the dimensions of decision-making, political activity, management of uncertainty, and internal and external adaptation. Our analysis was based on a sample of 70 separate primary insurers, who completed a questionnaire covering 60 relevant dimensions.

Our results highlight partial differences between the countries representing two different regulatory environments (Switzerland vs Germany/Austria), differences due to the business mix (life vs non-life), and differences based on firm size. Swiss firms perceive the pace of change to be significantly lower and the preparation time as tight but not as much as German and Austrian companies do. Surprisingly, Swiss firms differ most markedly from those in Germany, whereas Austrian firms are seen to be less concerned about upcoming regulations. Furthermore, our study supports the argument that life insurance firms are more affected than non-life insurance firms. Life insurers perceive the scope of solvency regulation and the uncertainty about regulatory change to be greater. Significant differences between life and non-life insurers are seen for the strategic adaptation dimensions. Large firms expect more opportunities from new regulation but they perceive a greater magnitude and have to cope with greater regulatory diversity.

Finally, we examined the additional role of the perceived effects of solvency regulation on (planned) strategic adaptation. Our results support the hypothesis that differences in the perceived effects do have significant additional explanatory power, affecting the (planned) sites and scope of business model adaptation. These findings deserve further research attention. As outlined already above, it is worth extending our study to other European countries and validating our findings by collecting data on real (compared with planned) adaptation. In addition, it is relevant to understand which adaptation strategies are more successful than others. For example, do insurance firms benefit from immediate compliance and more radical adaptation of their business model or more from a slower incremental adaptation path? Future research should also be directed towards a better understanding of how stricter solvency regulation affects policy issues and consumer protection.

\section{Acknowledgements}

The authors are grateful to Daniel Senn, Ronny Dormann, and Mathias Hausherr from KPMG Switzerland, as well as Christoph Lechner and Lyndon Oh from the Institute of Management, University of St. Gallen, for their valuable support in setting up the survey and identifying insurance firms for the data collection. In addition, the authors would like to thank the numerous senior insurance executives for their participation in the survey and the excellent discussions in extended interviews. 


\section{References}

Ashby, S. (2011) 'Risk management and the global banking crisis: Lessons for insurance solvency regulation', The Geneva Papers on Risk and Insurance - Issues and Practice 36(3): 330-347.

Birnbaum, P.H. (1984) 'The choice of strategic alternatives under increasing regulation in high technology companies', The Academy of Management Journal 27(3): 489-510.

Birnbaum, P.H. (1985) 'Political strategies of regulated organizations as functions of context and fear', Strategic Management Journal 6(2): 135-150.

Boston Consulting Group (BCG) (2010) The Solvency II Challenge: Anticipating the Far-Ranging Impact on Business Strategy, from www.bcg.com.

Butt, M. (2007) 'Insurance, finance, Solvency II and financial market interaction', The Geneva Papers on Risk and Insurance-Issues and Practice 32(1): 42-45.

Comité Européen des Assurances (CEA) (2007) Consequences of Solvency II Costs for Insurers' Administrative Costs, Technical Report.

Comité Européen des Assurances (CEA) (2010) 'Why Excessive Capital Requirements Harm Consumers, Insurers and the Economy', (March).

Committee of European Insurance and Occupational Pensions Supervisors (CEIOPS) (2009) 'Lessons Learned from the Crisis: Solvency II and Beyond'.

Cook, K., Shortell, S.M., Conrad, D.A. and Morrisey, M.A. (1983) 'A theory of organizational response to regulation: The case of hospitals', Academy of Management Review 8(2): 193-205.

Delmas, M., Russo, M. and Montes-Sancho, M. (2007) 'Deregulation and environmental differentiation in the electric utility industry', Strategic Management Journal 28(2): 189-209.

Doff, R. (2008) 'A critical analysis of the Solvency II proposals', The Geneva Papers on Risk and InsuranceIssues and Practice 33(2): 193-206.

Dutton, J.E. and Jackson, S.E. (1987) 'Categorizing strategic issues: Links to organizational action', Academy of Management Review 12(1): 76-90.

Eling, M., Gatzert, N. and Schmeiser, H. (2008) 'The Swiss Solvency Test and its market implications', The Geneva Papers on Risk and Insurance - Issues and Practice 33(3): 418-439.

Eling, M. and Holzmüller, I. (2008) 'An overview and comparison of risk-based capital standards', Journal of Insurance Regulation 26(4): 32-60.

Eling, M., Schmeiser, H. and Schmit, J. (2007) 'The solvency II process: Overview and critical analysis', Risk Management and Insurance Review 10(1): 69-85.

Engau, C., Hoffmann, V.H. and Busch, T. (2011a) 'Airlines flexibility in facing regulatory uncertainty: To anticipate or adapt?', California Management Review 54(1): 107-126.

Engau, C. and Hoffmann, V.H. (2011b) 'Corporate response strategies to regulatory uncertainty: Evidence from uncertainty about post-Kyoto regulation', Policy Sciences 44(1): 53-80.

European Commission (1999) 'The Review of the Overall Financial Position of an Insurance Undertaking', from www.ec.europa.eu/internal_market/insurance/docs/markt-2095/markt-2095-99_en.pdf.

European Commission (2010) 'Quantitative Impact Study 5 Technical Specifications', July.

European Commission (2011) 'Proposal for a Directive of the European Parliament and of the Council' ('Omnibus II' Directive).

European Insurance and Occupational Pensions Authority (EIOPA) (2011) 'QIS5 Results: General Findings, Surplus and Preparedness', from www.eiopa.europa.eu/fileadmin/tx_dam/files/consultations/ QIS/QIS5/HearingQIS5slides\%20[Compatibility\%20Mode].pdf.

European Union (2002a) 'Directive 2002/13/EC of the European Parliament and of the Council', Official Journal of European Communities, from http://eur-lex.europa.eu/en/index.htm

European Union (2002b) 'Directive 2002/83/EC of the European parliament and of the Council', Official Journal of European Communities, from http://eur-lex.europa.eu/en/index.htm

European Union (2009) 'Directive 2009/138/EC of the European parliament and of the Council', Official Journal of the European Union, (25 November), from http://eur-lex.europa.eu/en/index.htm

Flier, B., van den Bosch, F.A., Volberda, H.W., Carnevale, C.A., Tomkin, N., Melin, L., Quélin, B.V. and Kriger, M.P. (2001) 'The changing landscape of the European financial services sector', Long Range Planning 34(2): 179-207.

Fredrickson, J.W. (1984) 'The comprehensiveness of strategic decision processes: Extension, observations, future directions', The Academy of Management Journal 27(3): 445-466. 
Fredrickson, J.W. and Mitchell, T.R. (1984) 'Strategic decision processes: Comprehensiveness and performance in an industry with an unstable environment', The Academy of Management Journal 27(2): 399-423.

Hair, J., Black, W., Babin, B., Anderson, R. and Tatham, R. (2006) Multivariate Data Analysis, 6th edn., Upper Saddle River, NJ: Prentice-Hall.

Hauptman, O. and Roberts, E.B. (1987) 'FDA regulation of product risk and its impact upon young biomedical firms', Journal of Product Innovation Management 4(2): 138-148.

Haveman, H.A., Russo, M.V. and Meyer, A.D. (2001) 'Organizational environments in flux: The impact of regulatory punctuations on organizational domains, CEO succession, and performance', Organization Science 12(3): 253-273.

Heavey, C., Simsek, Z., Roche, F. and Kelly, A. (2009) 'Decision comprehensiveness and corporate entrepreneurship: The moderating role of managerial uncertainty preferences and environmental dynamism', Journal of Management Studies 46(8): 1289-1314.

Hillman, A.J., Keim, G.D. and Schuler, D. (2004) 'Corporate political activity: A review and research agenda', Journal of Management 30(6): 837-857.

Hoffmann, V.H., Trautmann, T. and Hamprecht, J. (2009) 'Regulatory uncertainty: A reason to postpone investments? Not necessarily', Journal of Management Studies 46(7): 1227-1253.

Hoffmann, V.H., Trautmann, T. and Schneider, M. (2008) 'A taxonomy for regulatory uncertaintyApplication to the European emission trading scheme', Environmental Science and Policy 11(8): 712-722.

Holzmüller, I. (2009) 'The United States RBC standards, Solvency II and the Swiss Solvency Test: A comparative assessment', The Geneva Papers on Risk and Insurance - Issues and Practice 34(1): 56-77.

IfB-HSG/KPMG (2011) 'Regulatorischer Wandel - Chancen und Risiken für die Versicherungsbranche', from www.kpmg.com.

I.VW-HSG/Accenture (2010) 'Insurance in 2015-Determining the Position: New Coordinates in the German-speaking Insurance Market', from www.ivw.unisg.ch.

I.VW-HSG/PricewaterhouseCoopers (PwC) (2011) 'Antworten mit Fragezeichen. IFRS 4 Phase II', from www.ivw.unisg.ch.

Jackson, S.E. and Dutton, J.E. (1988) 'Discerning threats and opportunities', Administrative Science Quarterly 33(3): 370-387.

Kim, B. and Prescott, J.E. (2005) 'Deregulatory forms, variations in the speed of governance adaptation, and firm performance', The Academy of Management Review 30(2): 414-425.

Klein, R.W. (2012) 'Principles for insurance regulation: An evaluation of current practices and potential reforms', The Geneva Papers on Risk and Insurance-Issues and Practice 37(1): 175-199.

Lant, T.K. and Mezias, S.J. (1992) 'An organizational learning model of convergence and reorientation', Organization Science 3(1): 47-71.

Lorson, J., Schmeiser, H. and Wagner, J. (2013) 'Evaluation of benefits and costs of insurance regulation a conceptual model for solvency II', Journal of Insurance Regulation, (forthcoming).

Meznar, M.B. and Nigh, D. (1995) 'Buffer or bridge? Environmental and organizational determinants of public affairs activities in American firms', The Academy of Management Journal 38(4): 975-996.

Morgan Stanley and Oliver Wyman Group (2010) Solvency 2: Quantitative \& Strategic Impact-The Tide is going Out, Technical Report.

Munch, P. and Smallwood, D.E. (1980) 'Solvency regulation in the property-liability insurance industry: Empirical evidence', The Bell Journal of Economics 11(1): 261-279.

Parker, A.R. (2001) 'Strategic choices in a dynamically changing deregulatory environment', Journal of Business Research 51(3): 201-208.

Pottier, S.W. (2010) 'Life insurer efficiency and state regulation: Evidence of optimal firm behavior', Journal of Regulatory Economics 39(2): 169-193.

PricewaterhouseCoopers (PwC) (2010) Getting set for Solvency II, Technical Report.

Rees, R., Gravelle, H. and Wambach, A. (1999) 'Regulation of insurance markets', The Geneva Papers on Risk and Insurance Theory 24(1): 55-68.

Russo, M. (1992) 'Power plays: Regulation, diversification, and backward integration in the electric utility industry', Strategic Management Journal 13(1): 13-27.

Swiss Federal Office of Private Insurance (FOPI) (2004) 'White Paper of the Swiss Solvency Test', from www.finma.ch/archiv/bpv/download/e/WhitePaperSST_en.pdf.

Thomas, J.B. and McDaniel Jr., R.R. (1990) 'Interpreting strategic issues: Effects of strategy and the informationprocessing structure of top management teams', The Academy of Management Journal 33(2): 286-306. 
Ungson, G., James, C. and Spicer, B.H. (1985) 'The effects of regulatory agencies on organizations in wood products and high technology/electronics industries', The Academy of Management Journal 28(2): 426-445.

Van Bragt, D., Steehouwer, H. and Waalwijk, B. (2010) 'Market consistent ALM for life insurers-Steps toward solvency II', The Geneva Papers on Risk and Insurance-Issues and Practice 35(1): 92-109.

Wagner, J. and Zemp, A. (2012) 'Comparison of stakeholder perspectives on current regulatory and reporting reforms', Risk Management and Insurance Review 15(2): 225-254.

Zott, C., Amit, R. and Massa, L. (2011) 'The business model: Recent developments and future research', Journal of Management 37(4): 1019-1042.

\section{Appendix}

\section{Survey questions}

\section{A. Solvency II and Swiss Solvency Test (SST) regulation}

A1. Magnitude of Solvency II/SST

To what extent do you agree/disagree with the following statements?

1. We face high levels of Solvency II/SST-related impact.

2. We deal with many regulatory agencies in connection to Solvency II/SST.

3. Regulatory requirements from Solvency II/SST affect a large part of our activities.

4. The intensity of solvency regulations we face vary widely across countries.

Scale: $1=$ strongly disagree, $5=$ strongly agree

\section{A2. Effect of Solvency II/SST}

To what extent do you agree/disagree with the following statements?

Solvency II/SST will have significant effects on ...

1. ... our products and services.

2. ... our capital structure.

3. ... our organisational structures and internal processes.

4. ... our risk management.

5. ... our profitability (Combined Ratio).

6. ... our firm's business model overall.

Scale: $1=$ strongly disagree, 5=strongly agree

\section{A3. Pace of Solvency II/SST}

To what extent do you agree/disagree with the following statements?

1. We had/have enough time to prepare for new Solvency II/SST.

2. Our business activities are quickly affected by new Solvency II/SST.

3. We face a rapidly changing regulatory environment due to Solvency II/SST.

Scale: $1=$ strongly disagree, $5=$ strongly agree

A4. Uncertainty of Solvency II/SST

Please indicate the degree of uncertainty your company holds with respect to the following features of a possible Solvency II/SST implementation.

1. The target state of Solvency II/SST is ... 
2. Political consensus among policymakers and interest groups on how to reach the target is ...

3. Specific measures and rules of forthcoming regulation are ...

4. Competence of regulators in implementing Solvency II/SST is ...

5. The interdependence with other regulations and reporting requirements is ...

6. Incentives it creates for our company's behaviour are ...

7. Strategic responses of our major competitors are ...

Scale: $1=$ highly uncertain, $5=$ highly certain

\section{A5. Solvency II/SST as threat or opportunity}

To what extent do you agree/disagree with the following statements?

1. We label Solvency II/SST as something positive.

2. We view Solvency II/SST with positive future implications for us.

3. We feel that there is a high probability of gaining a great deal from Solvency II/ SST.

4. We label Solvency II/SST as something negative.

5. We view Solvency II/SST with negative future implications for us.

6. We feel that there is a high probability of losing a great deal from Solvency II/ SST.

7. We feel we have the capability to address Solvency II/SST.

Scale: $1=$ strongly disagree, $5=$ strongly agree

B. Strategic adaptation to Solvency II/Swiss Solvency Test (SST)

B1. Decision-making comprehensiveness and Solvency II/SST

To what extent do you agree/disagree with the following statements?

1. We thoroughly examined potential threats and opportunities arising from Solvency II/SST.

2. We prepared detailed, technical reports on impact of Solvency II/SST on our firm.

3. We searched extensively for possible responses.

4. We developed many alternative possible responses.

5. We developed clear and diverse criteria for eliminating possible courses of action.

6. We thoroughly examined any suggested course of action.

Scale: $1=$ not at all, $5=$ to a very high extent

B2. Lobbying and political activity (Solvency II/SST)

Please rate the extent to which your company pursues the following activities to respond to (upcoming) Solvency II/SST:

1. We engage in the policy-making process.

2. We inform government decision-makers about the impact of possible solvency legislation.

3. We try to actively reduce government regulation of the firm. 
4. We work alone to make campaign contributions, lobby, or otherwise influence regulatory processes.

5. We work in trade associations to make campaign contributions, lobby, or otherwise influence regulatory processes.

6. We believe the above activities will have significant influence in producing our desired outcome.

Scale: $1=$ not at all, $5=$ to a very high extent

\section{B3. Managing uncertainty towards Solvency II/SST}

Please rate the extent to which your company pursues the following activities to respond to (upcoming) Solvency II /SST:

1. We anticipate(d) specific government regulation in order to ensure rapid compliance.

2. We track(ed) the development of regulation in order to have corporate compliance mechanisms in place by the time legislation is (was) enacted.

3. We postpone(d) our strategic decisions until we have (had) more certainty.

4. We shift(ed) our business to markets probably not affected by regulation.

5. We systematically search(ed) for additional information (e.g. talk to industry experts, consultants).

6. We narrow(ed) our focus to critical issues in our business environment.

7. We rearrange(d) our portfolio through mergers, acquisitions or divestitures to reduce our exposure to regulatory uncertainty.

8. We join(ed) forces with others, for example, suppliers, customers, or competitors.

9. We observe(d) the activities of other companies and follow them if appropriate.

10. We exceed compliance levels for Solvency II/SST regulation.

Scale: $1=$ not at all, $5=$ to a very high extent

B4. Scope of adaptation to Solvency II/SST

Facing Solvency II/SST, which of the following did you or will you substantially alter?

1. Business Model/product portfolio.

2. Business Strategy

3. Organisational Structure (create new divisions, shift functions between divisions).

4. Internal Power Distribution (e.g. change in functional backgrounds of our top management team).

5. Internal Control Systems (e.g. management information systems).

Scale: $1=$ no change, $5=$ high degree of change

B5. Sites of business model adaptation to Solvency II/SST

In the following business model areas, how do you intend to make the changes facing Solvency II/SST?

1. Product and service diversification.

2. Geographical diversification. 
3. Asset diversification.

4. Customer segments served.

5. Risk kept in-house (vs sourced out to external partners)

6. Product pricing.

Scale: $1=$ reduce, $5=$ increase

\section{Further results}

Table A1 Average ratings and significant differences for life and non-life insurers by country

\begin{tabular}{|c|c|c|c|c|c|c|c|c|c|}
\hline \multirow[t]{2}{*}{ Constructs } & \multicolumn{3}{|c|}{ Switzerland } & \multicolumn{3}{|c|}{ Germany } & \multicolumn{3}{|c|}{ Austria } \\
\hline & Life & Non-life & sig. & Life & Non-life & sig. & Life & Non-life & sig. \\
\hline \multicolumn{10}{|c|}{ Perceived impact of Solvency II/SST } \\
\hline Magnitude & 4.29 & 3.30 & $*$ & 4.27 & 4.47 & & 3.80 & 4.29 & \\
\hline Scope & 3.53 & 2.66 & $* *$ & 3.50 & 3.31 & & 3.77 & 3.23 & \\
\hline Scope diversity & 3.21 & 2.75 & & 2.43 & 2.06 & & 2.60 & 2.85 & \\
\hline Preparation time & 3.57 & 3.70 & & 2.13 & 2.44 & & 3.00 & 2.79 & \\
\hline Quickness of effects & 3.57 & 2.70 & & 3.30 & 3.44 & & 3.40 & 2.91 & \\
\hline Pace of change & 3.86 & 3.20 & $*$ & 3.83 & 4.03 & & 4.00 & 4.03 & \\
\hline Perceived certainty & 2.76 & 3.12 & & 2.18 & 2.41 & & 2.90 & 2.79 & \\
\hline Competitors & 2.86 & 2.89 & & 2.61 & 2.69 & & 2.40 & 2.82 & \\
\hline Opportunity & 3.76 & 3.07 & $*$ & 2.83 & 3.08 & & 3.33 & 2.73 & \\
\hline Threat & 1.95 & 1.80 & & 2.53 & 2.19 & & 1.93 & 2.06 & \\
\hline Capability & 4.00 & 4.20 & & 3.67 & 3.81 & & 4.00 & 4.06 & \\
\hline \multicolumn{10}{|c|}{ Strategic adaptation to Solvency II/SST } \\
\hline Decision comprehensiveness & 3.79 & 3.30 & & 3.42 & 3.36 & & 3.70 & 3.05 & $* *$ \\
\hline Political activity & 3.43 & 2.64 & & 3.09 & 2.81 & & 3.12 & 2.72 & \\
\hline Political bridging & 3.50 & 3.35 & & 3.52 & 3.42 & & 3.60 & 3.44 & \\
\hline Reduction strategy & 3.86 & 3.50 & & 3.72 & 3.80 & & 3.90 & 3.47 & $*$ \\
\hline Avoidance strategy & 1.79 & 1.85 & & 1.72 & 1.38 & & 1.80 & 1.38 & \\
\hline Postponement & 2.86 & 2.40 & & 2.90 & 2.47 & & 2.40 & 2.32 & \\
\hline Joined forces & 3.50 & 2.40 & $*$ & 2.07 & 2.41 & & 3.00 & 2.41 & \\
\hline Observation & 3.50 & 3.00 & & 3.10 & 3.41 & & 3.60 & 3.32 & \\
\hline Exceed compliance & 3.00 & 3.50 & & 2.30 & 2.88 & & 2.60 & 2.44 & \\
\hline Adaptation & 3.13 & 2.50 & & 3.24 & 2.72 & & 3.72 & 2.92 & $* * *$ \\
\hline External adaptation & 3.42 & 2.25 & $* *$ & 3.17 & 2.27 & $* *$ & 3.80 & 2.26 & $* * *$ \\
\hline Internal adaptation & 2.94 & 2.67 & & 3.29 & 3.02 & & 3.67 & 3.36 & \\
\hline Product diversification & 3.83 & 3.00 & $* *$ & 3.89 & 2.69 & $* * *$ & 4.00 & 3.06 & $* * *$ \\
\hline Geographical diversification & 2.50 & 3.00 & & 2.43 & 3.00 & & 2.40 & 3.00 & \\
\hline Asset diversification & 3.43 & 3.22 & & 3.57 & 3.53 & & 4.00 & 3.28 & $*$ \\
\hline Served customers & 3.43 & 3.11 & & 3.18 & 3.00 & & 3.20 & 3.28 & \\
\hline In-house risks & 3.00 & 3.22 & & 2.82 & 2.88 & & 3.20 & 2.94 & \\
\hline Product pricing & 4.00 & 3.44 & & 3.36 & 3.06 & & 4.20 & 3.31 & $* * *$ \\
\hline
\end{tabular}

Mean ratings and significant differences (sig.) for life and non-life companies in Switzerland, Germany and Austria are presented. Numbers represent the average rating and asterisks denote the significant differences among the categories considered. $*, * *$ and $* * *$ denote significance at the 10,5 and 1 per cent levels, respectively. 
Table A2 Average ratings and significant differences for large and small insurers by country

\begin{tabular}{|c|c|c|c|c|c|c|c|c|c|}
\hline \multirow[t]{2}{*}{ Constructs } & \multicolumn{3}{|c|}{ Switzerland } & \multicolumn{3}{|c|}{ Germany } & \multicolumn{3}{|c|}{ Austria } \\
\hline & Large & Small & sig. & Large & Small & sig. & Large & Small & sig. \\
\hline \multicolumn{10}{|c|}{ Perceived impact of Solvency II/SST } \\
\hline Magnitude & 4.33 & 3.00 & $* *$ & 4.36 & 4.39 & & 4.00 & 4.22 & \\
\hline Scope & 3.25 & 2.75 & & 3.44 & 3.30 & & 3.71 & 3.27 & \\
\hline Scope diversity & 3.61 & 2.19 & $* *$ & 2.32 & 2.00 & & 3.00 & 2.75 & \\
\hline Preparation time & 3.44 & 3.88 & & 2.18 & 2.56 & & 3.00 & 2.81 & \\
\hline Quickness of effects & 3.33 & 2.75 & & 3.20 & 3.78 & $*$ & 3.25 & 2.97 & \\
\hline Pace of change & 3.67 & 3.25 & & 3.89 & 4.06 & & 4.00 & 4.03 & \\
\hline Perceived certainty & 2.81 & 3.15 & & 2.36 & 2.16 & & 2.88 & 2.81 & \\
\hline Competitors & 3.00 & 2.71 & & 2.57 & 2.88 & & 3.25 & 2.61 & $*$ \\
\hline Opportunity & 3.63 & 3.04 & & 3.05 & 2.74 & & 3.33 & 2.76 & \\
\hline Threat & 1.93 & 1.79 & & 2.30 & 2.48 & & 2.00 & 2.04 & \\
\hline Capability & 4.00 & 4.25 & & 3.73 & 3.78 & & 4.25 & 4.00 & \\
\hline \multicolumn{10}{|c|}{ Strategic adaptation to Solvency II/SST } \\
\hline Decision comprehensiveness & 3.70 & 3.27 & & 3.50 & 3.13 & & 3.83 & 3.06 & $* *$ \\
\hline Political activity & 3.53 & 2.33 & $* *$ & 3.10 & 2.57 & & 3.30 & 2.71 & \\
\hline Political bridging & 3.56 & 3.25 & & 3.53 & 3.31 & & 4.13 & 3.33 & $* * *$ \\
\hline Reduction strategy & 3.89 & 3.38 & & 3.76 & 3.75 & & 4.00 & 3.47 & \\
\hline Avoidance strategy & 2.06 & 1.56 & & 1.67 & 1.22 & $* *$ & 1.63 & 1.44 & \\
\hline Postponement & 2.89 & 2.25 & & 2.75 & 2.50 & & 2.00 & 2.42 & \\
\hline Joined forces & 3.50 & 2.13 & $* *$ & 2.41 & 1.83 & & 3.00 & 2.44 & \\
\hline Observation & 3.25 & 3.13 & & 3.34 & 3.06 & & 3.00 & 3.47 & $* *$ \\
\hline Exceed compliance & 2.88 & 3.75 & & 3.02 & 1.56 & $* * *$ & 3.25 & 2.31 & $* *$ \\
\hline Adaptation & 2.98 & 2.50 & & 3.06 & 2.74 & & 3.35 & 3.05 & \\
\hline External adaptation & 3.13 & 2.25 & & 2.93 & 2.14 & & 3.13 & 2.50 & \\
\hline Internal adaptation & 2.88 & 2.67 & & 3.15 & 3.15 & & 3.50 & 3.42 & \\
\hline Product diversification & 3.63 & 3.00 & $*$ & 3.48 & 2.63 & $*$ & 3.50 & 3.24 & \\
\hline Geographical diversification & 2.63 & 3.00 & & 2.64 & 3.00 & & 2.50 & 2.94 & \\
\hline Asset diversification & 3.33 & 3.29 & & 3.59 & 3.44 & & 3.50 & 3.44 & \\
\hline Served customers & 3.33 & 3.14 & & 3.25 & 2.63 & $* *$ & 3.25 & 3.26 & \\
\hline In-house risks & 3.00 & 3.29 & & 2.89 & 2.75 & & 3.50 & 2.88 & \\
\hline Product pricing & 3.89 & 3.43 & & 3.18 & 3.25 & & 3.50 & 3.53 & \\
\hline
\end{tabular}

Mean ratings and significant differences (sig.) for large and small companies in Switzerland, Germany and Austria are presented. Numbers represent the average rating and asterisks denote the significant differences among the categories considered. $*, * *$ and $* * *$ denote significance at the 10,5 and 1 per cent levels, respectively. 


\begin{abstract}
About the Authors
Markus Kreutzer is Assistant Professor of Strategic Management at the University of St. Gallen's Institute of Management. He is also a Member of the Steering Committee of the Profile Unit Responsible Corporate Competitiveness (RoCC). He holds a PhD in management from the University of St.Gallen and a Master's degree in business administration and in economics from the University of Passau. His research interests include business models, strategic renewal, and coordination and control.
\end{abstract}

Joël Wagner is Assistant Professor of Risk Management and Insurance at the University of St. Gallen's Institute of Insurance Economics. He is also a Member of the Steering Committee of the Profile Unit Responsible Corporate Competitiveness (RoCC). Before, he was a consultant in the Financial Services and Insurance practice of The Boston Consulting Group. He holds a PhD in mathematics and an engineering degree in physics from the Swiss Federal Institute of Technology in Lausanne. His research interests include a range of topics in risk management and insurance with particular focus on recent developments in regulatory and reporting frameworks as well as the analysis of challenges in insurance management. 